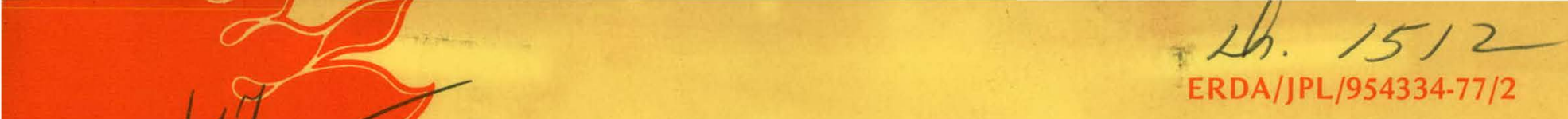

\title{
LOW COST SILICON SOLAR ARRAY PROJECT \\ Establishment Of The Feasibility Of Process Capable of Low Cost, High Volume Production Of Silane (Phase I), And The Pyrolysis of Silane To Semiconductor-Grade Silicon (Phase II) \\ Quarterly Progress Report, January-March 1977
}

\author{
W. C. Breneman \\ E. G. Farrier \\ J. Y. P. Mui \\ J. Rexer
}

1977

Work Performed Under Contract No. NAS-7-100-954334

Chemicals and Plastics Union Carbide Corporation Sistersville, West Virginia

Carbon Products Division Union Carbide Corporation Parma, Ohio

\section{ENERGY RESEARCH AND DEVELOPMENT ADMINISTRATION Division of Solar Energy}




\section{DISCLAIMER}

This report was prepared as an account of work sponsored by an agency of the United States Government. Neither the United States Government nor any agency Thereof, nor any of their employees, makes any warranty, express or implied, or assumes any legal liability or responsibility for the accuracy, completeness, or usefulness of any information, apparatus, product, or process disclosed, or represents that its use would not infringe privately owned rights. Reference herein to any specific commercial product, process, or service by trade name, trademark, manufacturer, or otherwise does not necessarily constitute or imply its endorsement, recommendation, or favoring by the United States Government or any agency thereof. The views and opinions of authors expressed herein do not necessarily state or reflect those of the United States Government or any agency thereof. 


\section{DISCLAIMER}

Portions of this document may be illegible in electronic image products. Images are produced from the best available original document. 


\section{NOTICE}

This report was prepared as an account of work sponsored by the United States Government. Neither the United States nor the United States Energy Research and Develupmenl Administration, nor any of their employees, nor any of their contractors, subcontractors, or their employees, makes any warranty, express or implied, or assumes any legal liability or responsibility for the accuracy, completeness or usefulness of any information, apparatus, product or process disclosed, or represents that its use would not infringe privately owned rights.

This report has been reproduced directly from the best available copy.

Available from the National Technical Information Service, U. S. Department of Commerce, Springfield, Virginia 22161

Price: Paper Copy $\$ 4.50$ (domestic)

$\$ 7.00$ (foreign)

Microfiche $\$ 3.00$ (domestic)

$\$ 4.50$ (foreign) 


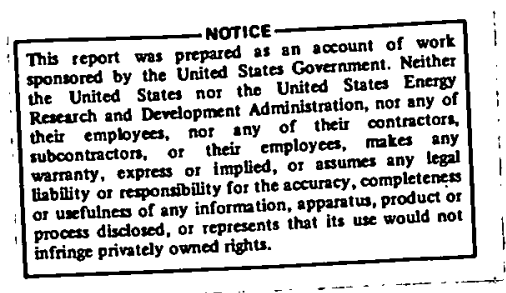

ERDA/JPL/954334-77/2

Distribution Category UC.63b

$\underline{\text { PART VI }}$

A PROCESS FOR HIGH VOLUME LOW COST PRODUCTION OF SILANE SILICON MATERIAL TASK OF THE LOW COST SILICON SOLAR ARRAY PROJECT

\begin{tabular}{|c|c|c|}
\hline AUTHORS : & $\begin{array}{l}\text { W. C. Breneman } \\
\text { J. Y. P. Mui }\end{array}$ & April 1, 1977 \\
\hline WORK BY: & $\begin{array}{l}\text { W: C. Breneman } \\
\text { J.Y. P. Mui } \\
\text { R. L. Ocheltree }\end{array}$ & PROJECT NUMBER: 486580 \\
\hline SUPERVISORS : & $\begin{array}{l}\text { L. Madestau } \\
\text { B. Kanner }\end{array}$ & FILE NUMBER: SVP-77-20 \\
\hline
\end{tabular}

$\underline{\text { SUMMARY }}$

A mini-plant for producing silane from dichlorosilane via a redistribution reaction has produced $97 \%$ pure $\mathrm{SiH}_{4}$ at 938 efficiency. The residual impurities were monochlorosilane (2.5\%) and dichlorosilane (.5\%). The silane purity of $97 \%$ achieved by operating the silane still partial condenser at 40 psig and $-32^{\circ} \mathrm{C}$ outlet temperature was significantly higher than predicted by ideal vapor-liquid equilibrium considerations. Laboratory equilibrium concentrations and order of magnitude reaction rates were confirmed in mini-plant operations. Kinetic isotope studies on the mechanism of the amine catalyzed redistribution of chlorosilanes indicated the amine hydrochloride may not be the active speciesas originally proposed. The hydrogenation of silicon tetrachloride to trichlorosilane appears to be a true equilibrium, approachable from either $\mathrm{HSiCl}_{3}$ or $\mathrm{SLCl}_{4}$. Virtually no $\mathrm{H}_{2} \mathrm{SiCl}_{2}$ was formed by hydrogenation of $\mathrm{HSiCl}_{3}$.

This work was performed for the Jet Propulsion Laboratory, California Institute of Technology under NASA Contract NAS 7-100 for the U.S. Energy Research and Development Administration Division of Solar Energy.

UNION CARBIDE CORPORATION - CHEMICALS AND PLASTICS RESEARCH AND DEVELOPMENT DEPARTMENT

SISTERSVILLE, WEST VIRGINIA 
TABLE OF CONTENTS

\section{ABSTRACT}

INTRODUCTION $\ldots \ldots \ldots \ldots \ldots \ldots \ldots \ldots \ldots \ldots \ldots \ldots \ldots \ldots \ldots \ldots \ldots \ldots \ldots$

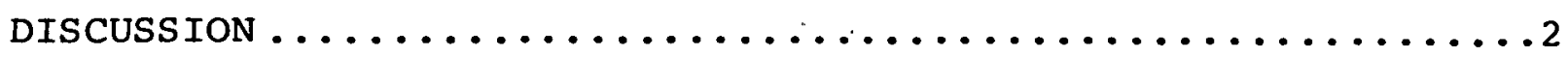

1. Silane Mini-Plant Operations ..................

2. Hydrogenation of $\mathrm{SiCl}_{4} \ldots \ldots \ldots \ldots \ldots \ldots \ldots \ldots$

3. Hydrogenation Reactor Design .................... 15

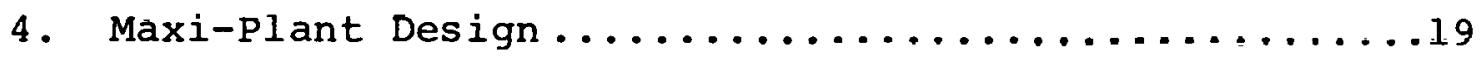

5. Reartion Mechaniom Etudies .................... 19

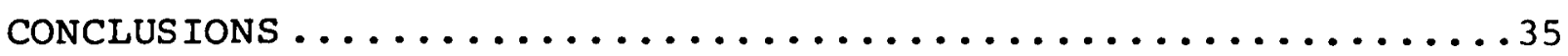

PROJECTED SEVENTH QUARTER ACTIVITIES ......................

SECTION B - SILANE PYROLYSIS. ........................ 39

List of Figures

1. Silane Mini-Plant Simplified Flow Path..............4

2. Silane Purity vs still Condenser Pressure .............

3. Silane Mini-Plant Molar Composition Profile...........7

4. Fixed Bed Hydrogenation Reactor ...................

5. Fixed Bed Hydrogenation Composition ................12

6. Silane Maxi-Plant Proposed Flow Sheet................20

7. Apparatus for Quantitative Infrared Analysis .........26

8. Plot of $\mathrm{SiH}$ Absorbance vs $\mathrm{HSiCl}_{3}$ Concentration .........28

9. Plot of giD Absorbance vs $\mathrm{DS}_{\mathrm{C}} \mathrm{l}_{3}$ Concentration .........29

10. Laboratory Redistribution Reactor .................. 32

- 11. Total Cost/Man Hour Plan ........................... 37

12. Revised Implementation $\operatorname{Plan} \ldots \ldots \ldots \ldots \ldots \ldots \ldots \ldots \ldots \ldots$ 


\section{LIST OF: TABLES}

I Hydrogenation of $\mathrm{SiCl}_{4}$ to $\mathrm{HSiCl}_{3}$ at $500^{\circ}$ Atmospheric Pressure with $\mathrm{l}: 1 \mathrm{SiCl}_{4}$ to $\mathrm{H}_{2}$ Over 220 Grams of $\mathrm{Cu} / \mathrm{Si}$ Contact Mass in a Fluidized Bed Reactor................10

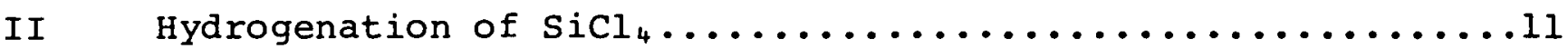

II-a Hydrogenation of $\mathrm{SiCl}_{4}$ to $\mathrm{HSiCl}_{3}$ at Low Reactor

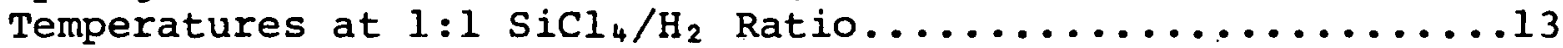

II Summary of Data on the Hydrogenation of $\mathrm{HSiCl}_{3}$ in a

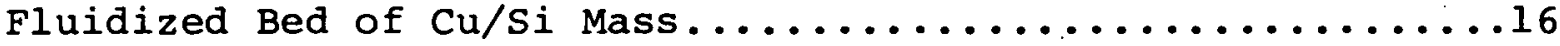

IV Hydrogenation Reactor Design, Summary................18

$V$ Direct Reaction of $\mathrm{HCl}$ Gas With Si Metal at $320^{\circ}$,

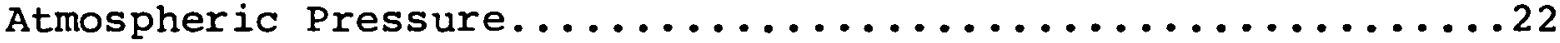

VI Direct Reaction of DCl Gas With Si Metal at $320^{\circ}$, Atmospheric Pressure..........................23

VII Disproportionation of $\mathrm{HSiCl}_{3}$ and $\mathrm{DCl}$ Gas in the Pressure

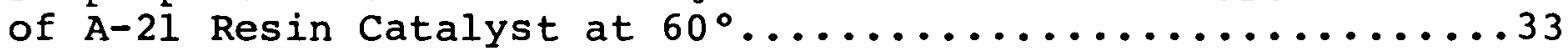




\section{ABSTRACT}

A mini-plant for producing silane from dichlorosilane via a redistribution reaction has produced 978 pure $\mathrm{SiH}_{4}$ at 93\% efficiency. The residual impurities were monochlorosilane (2.5\%) and dichlorosilane (.5\%). The silane purity of $97 \%$ achieved by operating the silane still partial condenser at 40 psig and $-32^{\circ} \mathrm{C}$ outlet temperature was significantly higher than predicted by ideal vapor-liquid equilibrium considerations. Laboratory equilibrium concentrations and order of magnitude reaction rates were confirmed in mini-plant operations. Kinetic isotope studies on the mechanism of the amine catalyzed redistribution of chlorosilanes indicated the amine hydrochloride may not be the active speciesas originally proposed. The hydrogenation of silicon tetrachloride to trichlorosilane appears to be a true equilibrium, approachable from either $\mathrm{HSiCl}_{3}$ or $\mathrm{SiCl}_{4}$. Virtually no $\mathrm{H}_{2} \mathrm{SiCl}_{2}$ was formed by hydrogenation of $\mathrm{HSiCl}_{3}$. 


\section{INTRODUCTION}

This research program commenced October 6, 1975. Its purpose is to determine the feasibility for the high volume, low cost production of silane $\left(\mathrm{SiH}_{4}\right)$ as an intermediate raw material for solar grade silicon metal. The process to be investigated is based on the synthesis of $\mathrm{SiH}_{4}$ by the catalytic redistribution of chlorosilanes. The goal is to demonstrate the feasibility for a large scale (approximately 1000 metric tons per year) production cost of under $\$ 4.00$ per kilogram of $\mathrm{SiH}_{4}$.

Prior to the inception of this program workers at Union Carbide have shown experimentally that pure chlorosilanes can be redistributed into an equilibrium mixture of other hydrochlorosilanes by contact with a tertiary amine ion exchange resin. Patents rights for that process and improvements there on have been filed.

Up through the previous quarter, laboratory work has determined the equilibrium composition and reaction rate for vapor redistribution of dichlorosilane and trichlorosilane as cata?yzed by a macroreticular tertiary amine functional ion exchange resin. At $80^{\circ} \mathrm{C}$ for example, the effluent vapor contained fourteen mole percent $\mathrm{SiH}_{4}$ at equilibrium when the feed was pure dichlorosilane. The reaction half time was 0.25 seconds. In the case of trichlorosilane, the equilibrium composition was slightly less than ten mole percent dichlorosilane at 10 seconds half time.

Also studied was a method to remove traces of chlorosilanes from silane using a porous activated carbon.

The major co-product of the redistribution process is silicon tetrachloride as can be seen from the following chemical reaction. path:
$2 \mathrm{HSiCl}_{3} \rightleftharpoons \mathrm{H}_{2} \mathrm{SiCl}_{2}+\mathrm{SiCl}_{4}$
$3 \mathrm{H}_{2} \mathrm{SiCl}_{2} \rightleftharpoons 2 \mathrm{HSiCl}_{3}+\mathrm{SiH}_{4}$
Overall $4 \mathrm{HSiCl}_{3} \longrightarrow 3 \mathrm{SiCl}_{4}+\mathrm{SiH}_{4}$

A second part of this program is to study the hydrogenation of silicon tetrachloride both as a method of recovering this coproduct and as a means for consuming metallurgical grade silicon metal which, after all, is the object of the program, e.g. to convert impure silicon metal into high purity silicon metal by chemical means. The previous work showed that at circa $550^{\circ} \mathrm{C}$ silicon tetrachloride can be hydrogenated to trichlorosilane while consuming silicon metal according to the reaction:
$3 \mathrm{SiCl}_{4}+$
$2 \mathrm{H}_{2}+$
$\mathrm{Si} \underset{\mathrm{Cu}}{\stackrel{550^{\circ}}{\longrightarrow}} 4 \mathrm{HSiCl}_{3}$ 
The equilibrium composition at 1 atmosphere pressure and at 1 mole of $\mathrm{H}_{2}$ per mole of $\mathrm{SiCl}_{4}$ was about 20 mole percent $\mathrm{HSiCl}_{3}$. Thus, a close cycle process was possible for converting metallurgical silicon to high purity silicon using silane as the primary intermediate:

$\mathrm{Si}(\mathrm{M} . \mathrm{G})+.3 \mathrm{SiCl}_{3}+2 \mathrm{H}_{2} \longrightarrow 4 \mathrm{HSiCl}_{3}$ Hydrogenation

$4 \mathrm{HSiCl}_{3} \longrightarrow 2 \mathrm{H}_{2} \mathrm{SiCl}+2 \mathrm{SiCl}_{4} \quad$ Redistribution

$2 \mathrm{H}_{2} \mathrm{SiCl}_{2} \longrightarrow \mathrm{SiCl}_{4}+\mathrm{SiH}_{4} \quad$ Redistribution

$\mathrm{SiH}_{4} \longrightarrow 2 \mathrm{H}_{2}+\mathrm{Si}$ (Pure) Pyrolysis

net $\mathrm{Si}\left(\mathrm{M.G.)}+2 \mathrm{H}_{2} \longrightarrow \mathrm{Si}\right.$ (Pure) $+2 \mathrm{H}_{2}$

The impurities being removed, of course, in the process of refining the $\mathrm{SiH}_{4}$.

A mini-plant has been constructed to study the conversion of dichlorosilane to silane. At the beginning of this quarter, the unit was mechanically complete and was in the process of undergoing a final pre-start up safety review.

In January, 1977 a major expansion of this program was initiated to study the pyrolysis of silane to silicon metal. Progress under that effort is reported in section $B$.

\section{DISCUSSION}

\section{Silane Mini-Plant Operations}

The silane mini-plant was certified for operation by a fivemember safety review team. The few minor modifications recommended were accomplished and the unit commissioned with dichlorosilane. For simplicity of start up, the silane product gas was vented to the atmosphere immediately downstream of the silane still. Shortly after the dichlorosilane feed was introduced, an orange flame appeared at the vent indicating the generation of silane. The flame was extinguished by nitrogen purge. During the initial run, the various controllers and indicators were aligned and the on-line 
chromatograph sampling system checked out. A modification of the condensate recycle from the silane still to the reboiler was made to reduce a vapor lock problem, an oversized feed control valve was replaced. with a smaller one and several other minor running adjustments were made.

The goal was to determine the unit's operational limits and the quality and quantity of silane which would result. It was quickly learned that the overall production rate of $\mathrm{SiH}_{4}$ would be not much more than $100 \mathrm{gram} / \mathrm{hour}$ due to the pressure drop in the system from the vaporizer through the packed bed resin reactor and distillation column (Figure 1 ). At recycle flows higher than $4000 \mathrm{gram} / \mathrm{hour}$ of dichlorosilane (DCS) the total pressure drop exceeded the effective liquid height in the condensate return line to the vaporizer and hence, blocked the recycle of unconverted DCS. For example, the pressure drop profile revealed the following:

Across flow meter DPX-1

Across resin bed

Across distillation column

Total pressure drop
48 inches of water

13

$\underline{35}$

$96 "$ of water

This was at a flow rate of $7,137 \mathrm{~g} / \mathrm{hr}$ of $\mathrm{DCS}$. The available liquid head was on the order of 60" of water for the gravity recycle of distillate to the vaporizer. Since the major resistance was due to the flow measuring element, a larger orifice was installed and the pressure drop range lowered to 20 inches at maximum flow of $53 \mathrm{~kg} / \mathrm{hr}$ of $\mathrm{DCS}$.

The purity of the silane gas with respect to the other chlorosilanes reached a maximum of 97 mole $\%$. This was achieved by increasing the system pressure to $269 \mathrm{kpa}$ (39 psig) and operating the partial condenser on the silane still at $-30^{\circ} \mathrm{C}$ outlet temperature. The silicon tetrachloride scrubber and carbon purification traps were not in use at that time.

Assuming ideal vapor-liquid equilibrium behavior, a purity of $92 \% \mathrm{SiH}_{4}$ could be obtained with the condenser operating at $-30^{\circ} \mathrm{C}$ (and $39 \mathrm{psig}$ ). The fact that the 96-97\% value was maintained for a period of over two hours at $-30^{\circ} \mathrm{C}$ would indicate a stable condition and that there may be sufficient variation from ideal behavior to result in a significant enhancement of $\mathrm{SiH}_{4}$ purity. Figure 2 plots the experimental silane purity at $-30^{\circ} \mathrm{C}$ condenser temperature versus system pressure along with the ideal behavior prediction.

The initial compositional profiles at various points in the unit are shown in Figure 3. These results were obtained by on-line gas chromatography analysis. As can be seen, DCS containing a small amount of monochlorosilane (MCS) and trichlorosilane (TCS) from the internal recycle of the still condensate is converted to 


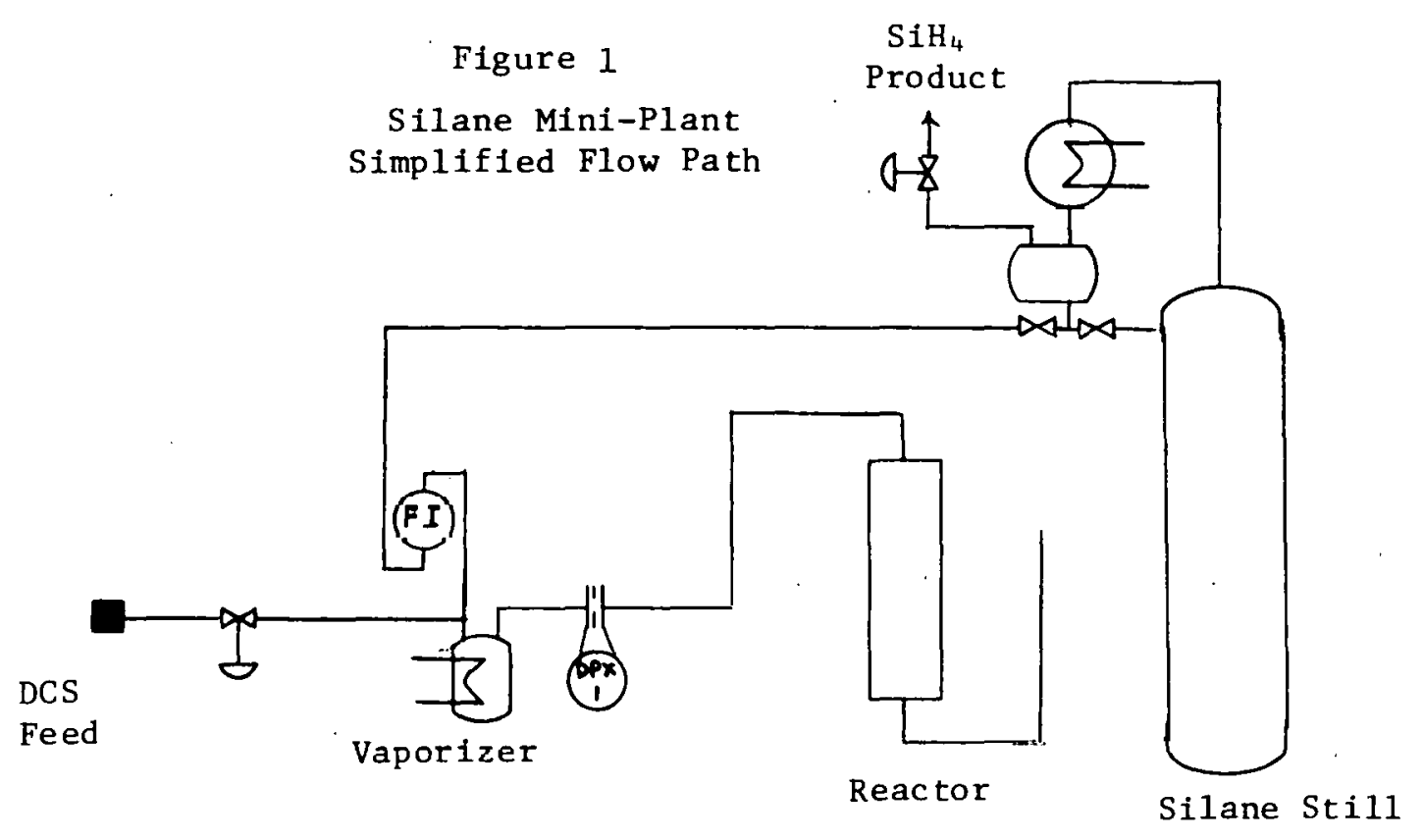


Figure 2

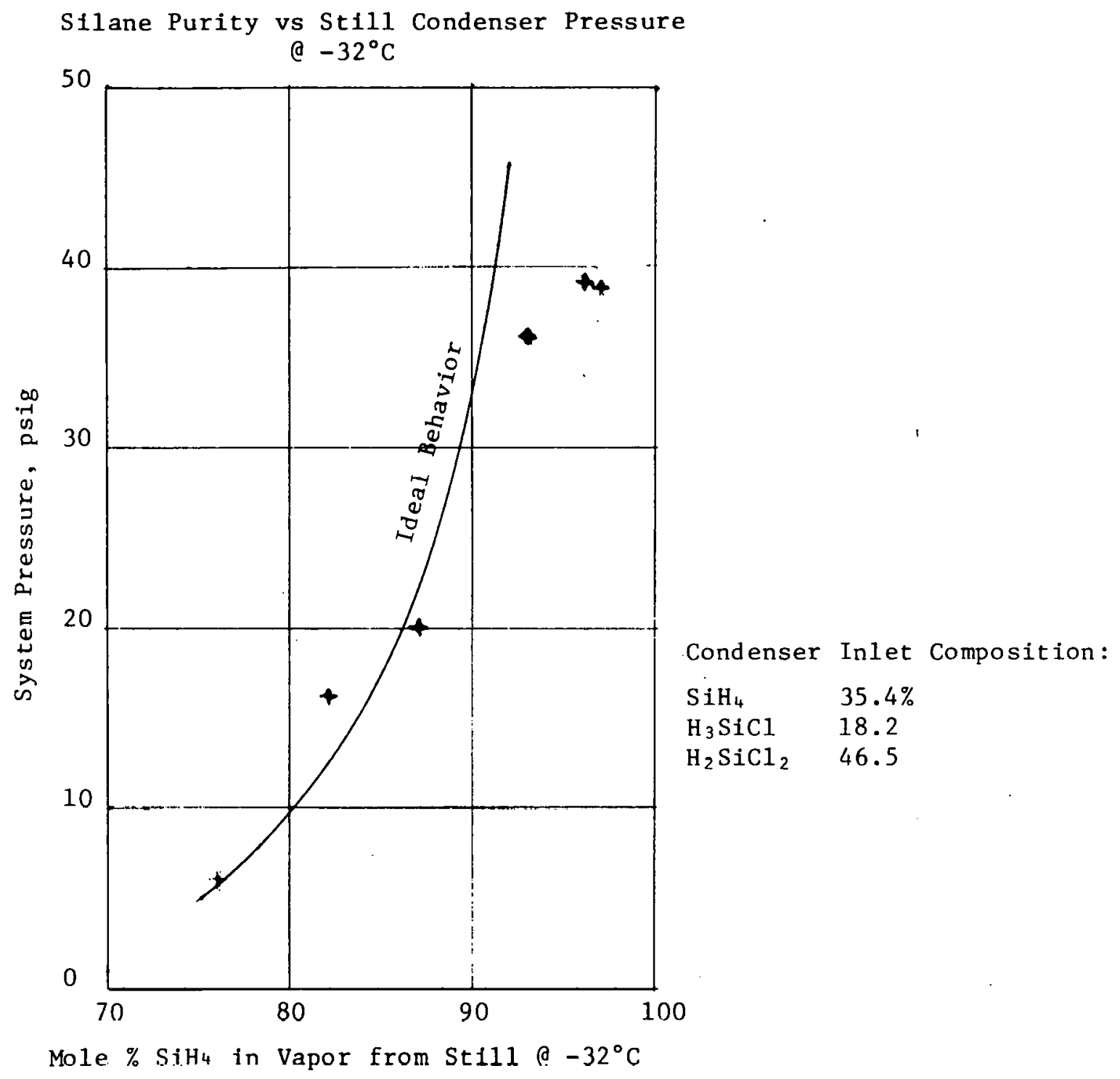


a mixture of silanes at the reactor outlet. Essentially no inert gas $\left(\mathrm{N}_{2}\right)$ of other extraneous compounds are present in the chromatogram. The reactant effluent mixture is separated in the 1 "

I.D. x $4 \mathrm{ft}$. high distillation column. Operating, for example, at 16 psig, 1:1 reflux ratio and a condensate temperature of $-28^{\circ} \mathrm{C}$, the non-condensed gas product analyzed at over 81 mole $8 \mathrm{SiH}_{4}$. The bottoms product was analyzed as 88.6 mole 8 TCS. The mass balance indicated .8307 pound of TCS for each 1.0 pound of DCS feed - or $93 \%$ yield assuming the net reaction to be:

$$
3 \mathrm{H}_{2} \mathrm{SiCl}_{2} \longrightarrow 2 \mathrm{HSiCl}_{3}+\mathrm{SiH}_{4}
$$

The control of the silane still to maximize silane purity and dichlorosilane efficiency was reasonably straightforward. The reflux ratio was decreased (at constant feed and reboiler heat input) until the reboiler temperature reached the TCS boiling point and the head temperature was between the DCS and TCS boiling point preferably closer to DCS. It was important to not apply so much reflux as to drop the head temperature below the DCs boiling point. When this was done, the DCS was accumulated in the column, eventually leaving via the reboiler. The silane purity was controlled by the still pressure and condenser temperature as discussed above. The unconverted DCS and any MCS and TCS is recycled to the vaporizer from which, mixed with sufficient fresh DCS to maintain a constant flow rate, it is then passed over the resin catalyst and into the distillation column. By coupling the DCS feed valve to the flow meter downstream of the vaporizer, the unit consummed DCS only at the same rate as material flowed from the constant level reboiler with the silane gas exiting the condenser.

The original process scheme called for a silane crude gas purity of $80 \%$ to be enriched to $99+\%$ by adsorption of the MCS and DCS using cold $\left(-40^{\circ} \mathrm{C}\right)$ silicon tetrachloride (STC). When the adsorber/stripper section of the mini-plant was brought on stream, the anticipated purification was not achieved. According to design calculations, 5 to $7 \mathrm{~kg}$ of STC would be required per $\mathrm{kg}$ of $\mathrm{SiH} 4$. At the initial low production rate of about . $1 \mathrm{~kg} / \mathrm{hr}$ the requisite $.7 \mathrm{~kg} / \mathrm{hr}$ of STC was inadequate to overcome the inherent heat loss of the system. In addition, the transfer pump used to pump the saturated STC back to the stripper contributed a significant amount of heat and in effect caused any adsorbed MCS to be desorbed. At higher STC flows, too much $\mathrm{SiH}_{4}$ was adsorbed and subsequently lost out the stripper vent.

Several revisions have or soon will be implemented to demonstrate either the practicality of this purification technique or to utilize the enhanced purity available from the silane still to incorporate only a larger carbon purification unit. 


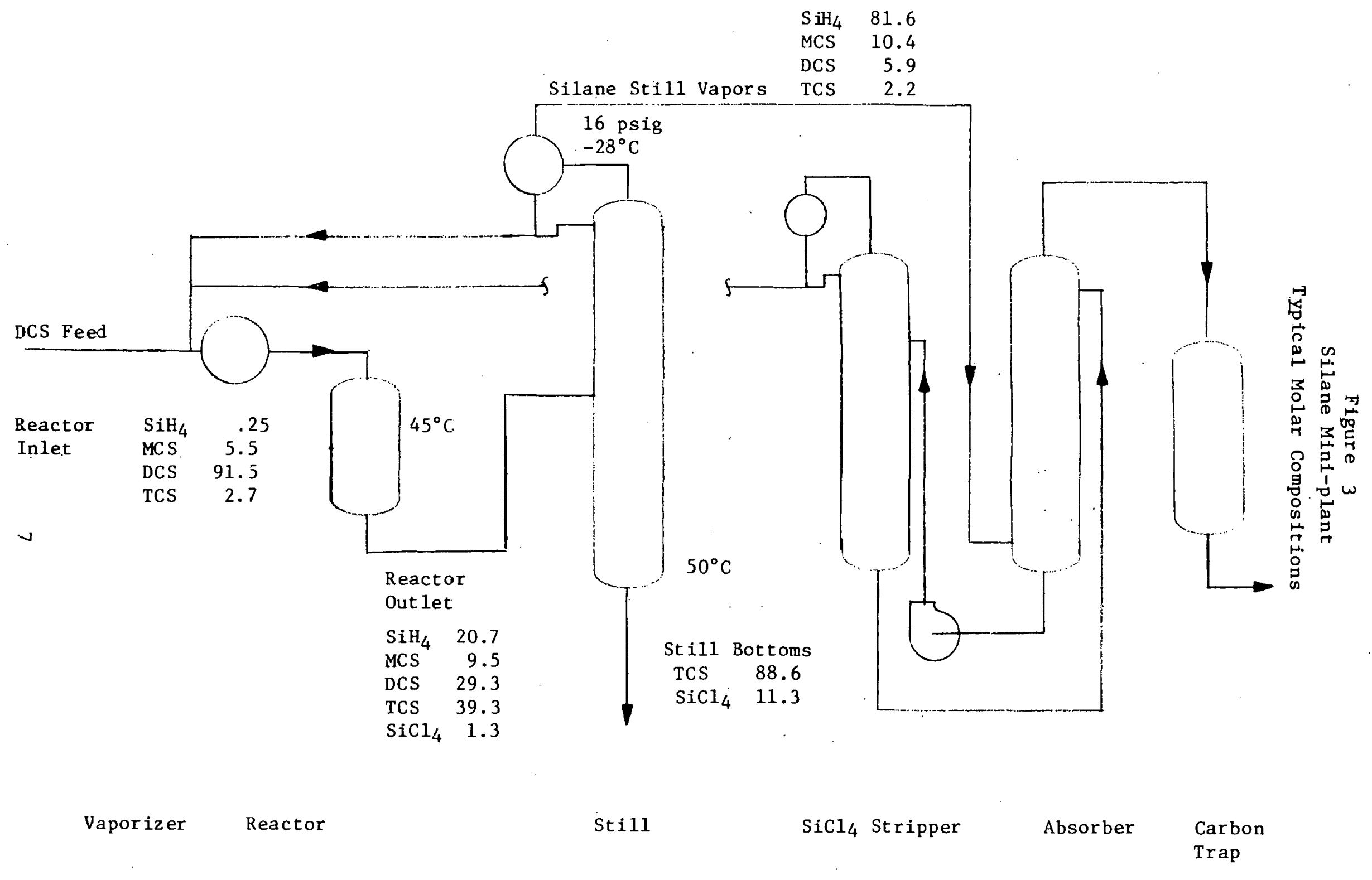




\section{Hydrogenation of $\mathrm{SiCl}_{4}$}

The hydrogenation of co-product $\mathrm{SiCl}_{4}$ to $\mathrm{HSiCl}_{3}$ while consuming metalurgical grade silicon metal is an essential feature of the silane via redistribution process scheme. In the commercial preparation of trichlorosilane by the hydrochlorination of metalurgical silicon, a fluidized bed reactor is often used to allow for ease in handling the silicon, provide high surface area for reaction (small particle size) and most important, provide excellent heat transfer to cool this highly exothermic reaction. The design of a reactor to produce TCS via hydrogenation of $\mathrm{SiCl}_{4}$ requires evaluation of a new set of criteria. The reaction is not strongly exothermic, is likely surface area dependent, requires a copper catalyst for high reaction rates, operates of circa $500^{\circ} \mathrm{C}$ and is potentially enhanced by higher operating pressure. Previous laboratory experiments have shown the utility of a fluidized bed for the hydrogenation reactor. To evaluate the desirability of a fixed bed design, a system shown in Figure 4 was assembled. Usinq $65 x 150$ mesh metalurgical silicon mixed with $1 \%$ cement copper catalyst contained in a $2.0 \mathrm{~cm} 1.0 \times 30 \mathrm{~cm}$ long quartz tube and heated by an electric tube furnace, a mixture of hydrogen and $\mathrm{SiCl}_{4}$ from a vaporizer was reacted at $550^{\circ} \mathrm{C}$.

Figure 4

Fixed Bed Hydrogenation Reactor

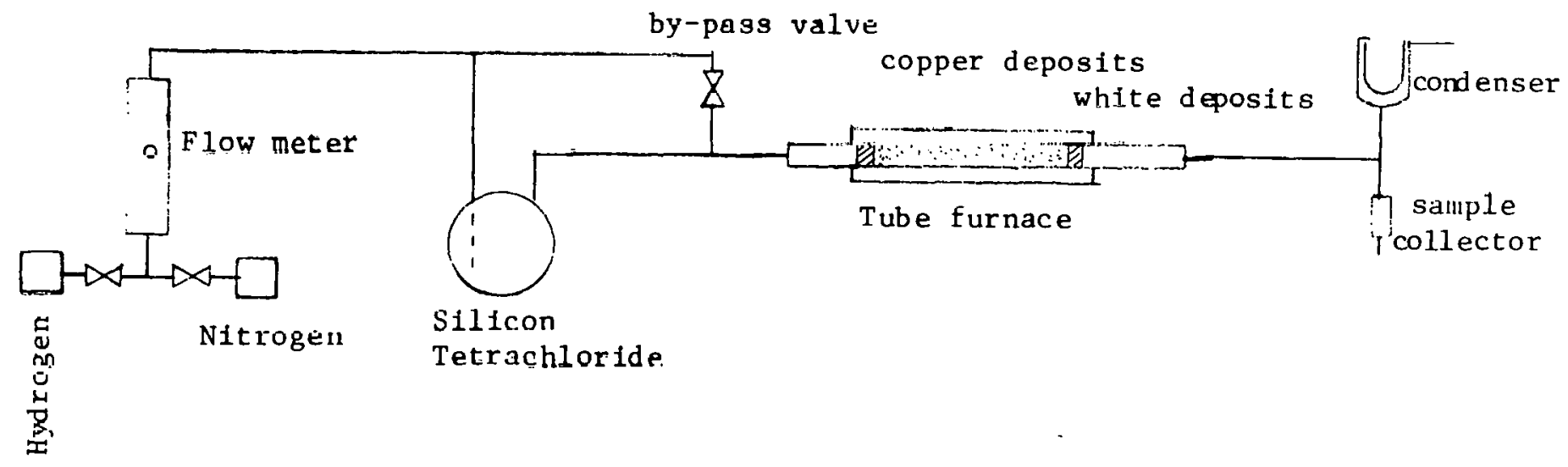


Table I lists the results of a series of runs at various $\mathrm{H}_{2}: \mathrm{SiCl}_{4}$ ratios and residence times using the fixed bed reactor. In general, as the $\mathrm{H}_{2}: \mathrm{SiCl}_{4}$ ratio increases and as the residence time increased, higher conversion to TCS was observed. However, when compared to the fluid bed reactor, it is clear that equilibrium conversion was not achieved.

The results of a 38 hour run, Figure 5, indicate a reaction rate again much lower than in the case of the fluidized bed. Visually, it was noted that a film of copper (or copper oxide) coated the tube near the inlet, that a film of white solids collected on the cooler portion of the tube downstream of the furnace, and that the silicon/copper mass after 40 hours of operation had several pea size agglomerants present. From the analysis of the residual silicon mass (Table II) and these observations it can be inferred that a fixed bed of relatively small particle size silicon (65 x 150 mesh) would not be a preferred reactor configuration. Upon scale up, problems with agglomeration would likely increase and the evidence of copper deposition on the reactor wall, along with low $\mathrm{SiCl}_{4}$ conversion, would indicate lower copper utilization and absence of active copper/silicon reaction sites. The white wall deposits on the exit tube analyzed rich in aluminum which is a major impurity in the metalurgical silicon metal.

A series of experiments on the hydrogenation of $\mathrm{SiCl}_{4}$ in a fluidized bed of $\mathrm{Cu} / \mathrm{Si}$ contact mass was carried out at reactor temperatures of $500^{\circ}, 450^{\circ}$, and $400^{\circ} \mathrm{C}$. These experiments were to supplement previous results ${ }^{1}$ on the hydrogenation of $\mathrm{SiCl}_{4}$ at higher reactor temperatures. The reaction was carried out in the same apparatus used in previous experiments. The Vycor glass fluidized bed reactor was charged with $200 \mathrm{~g}$ of. 65 x 150 mesh $\mathrm{Cu} / \mathrm{Si}$ contact mass containing about $1 \%$ copper catalyst. The contents were fluidized with a $1: 1$ molar mixture of $\mathrm{SiCl}_{4}$ and $\mathrm{H}_{2}$ gas at the selected reactor temperature. The residence time was also varied to measure the rate of reaction by changing the hydrogen gas feedrate. Results of these experiments were summarized in Table II. Experiment No. 1 in Table II was repetition of a similar experiment previously carried out at $500^{\circ}$. Agreement with previous results was good. Increase in residence time from 10.2 seconds (Experiment No. 1) to 28 seconds (Experiment No. 2) showed little change in the $\mathrm{HSiCl}_{3}$ yield of about $13.5 \%$. Thus, the hydrogenation reaction,

$$
3 \mathrm{SiCl}_{4}+2 \mathrm{H}_{2}+\mathrm{Si} \stackrel{\mathrm{Cu}}{\longleftarrow} 4 \mathrm{HSiCl}_{3}
$$

at $500^{\circ}$ had reached equilibrium in about 10 seconds or less. As shown in Table II, experiments No. 3, 4, and 5 were carried out at $450^{\circ}$ with residence times in $9.6,30$, and 60 seconds respectively. 
TABLE I

HYDROGENATION OF SICl, TO HSICl, AT $500^{\circ}$

ATMOSPHER IC PRESSURE WITH $1: 1$ SiCl " TO H OVER 220 GRAMS OF CU/Si CONTACT MASS IN A FLUIDIZED BED REACTOR

Weight of

Reaction Time Crude Collected Grams

Product Composition, Mole $\&$

(Reactor under nitrogen at $550^{\circ}$, cooled and shutdown overnight.)

$\begin{array}{llllll}4 & 64 & 0.14 & 8.59 & 90.72 & 0.55 \\ 5 & 65 & 0.14 & 9.97 & 89.52 & 0.36\end{array}$

(Clean Cu/Si mass again with $\mathrm{HCl}$ gas at $330^{\circ}$ to collect. 27 grams of crude.)

$\begin{array}{llllll}\overline{6} & 27 & 5.55 & 70.77 & 23.57 & 0.12 \\ 7 & 65 & 0.22 & 12.13 & 87.57 & 0.07 \\ 7 & 66 & 0.25 & 11.51 & 88.15 & 0.09\end{array}$

(Shutdown overnight under $\mathrm{SiCl}_{4} / \mathrm{H}_{2} \cdot$ )

$\begin{array}{rlllll}8 & 64 & 0.16 & 11.22 & 88.56 & 0.06 \\ 9 & 65 & 0.14 & 11.60 & 88.18 & 0.09 \\ 10 & 64 & 0.16 & 12.15 & 87.65 & 0.04 \\ 11 & 63 & 0.19 & 13.79 & 85.94 & 0.08 \\ 12 & 64 & 0.11 & 13.92 & 85.92 & 0.05 \\ 13 & 63 & 0.22 & 14.74 & 85.03 & 0.02\end{array}$

(Shutdown over weekend under $\mathrm{SiCl} \mathrm{H}_{4} / \mathrm{H}_{2}$. )

$\begin{array}{llllll}14 & 62 & 0.14 & 15.01 & 84.83 & 0.02 \\ 15 & 64 & 0.14 & 14.75 & 85.07 & 0.04 \\ 16 & 65 & 0.44 & 14.48 & 85.00 & 0.08 \\ 17 & 67 & 0.18 & 15.18 & 84.56 & 0.08 \\ 18 & 64 & 0.29 & 14.30 & 85.39 & 0.03 \\ 19 & 62 & 0.12 & 14.24 & 85.59 & 0.05\end{array}$

(Shutdown overnight under $\mathrm{SiCl}_{4} / \mathrm{H}_{2}$, )

$\begin{array}{llllll}20 & 61 & 0.10 & 14.27 & 85.55 & 0.08 \\ 21 & 61 & 0.17 & 14.38 & 85.34 & 0.11 \\ 22 & 62 & 0.20 & 14.93 & 84.76 & 0.11 \\ 23 & 61 & 0.19 & 15.04 & 84.73 & 0.04 \\ 24 & 82 & 0.13 & 13.26 & 86.59 & 0.02 \\ 25 & 82 & 0.16 & 13.82 & 86.00 & 0.02\end{array}$

(Shutdown overnight under $\mathrm{SiCl}_{4} / \mathrm{H}_{2}$ ))

$\begin{array}{llllll}26 & 65 & 0.16 & 13.51 & 86.25 & 0.08 \\ 27 & 70 & 0.15 & 14.36 & 85.43 & 0.06 \\ 28 & 67 & 0.17 & 14.38 & 85.43 & 0.02 \\ 29 & 70 & 0.18 & 14.54 & 85.24 & 0.04 \\ 30 & 64 & 0.17 & 14.55 & 85.25 & 0.04\end{array}$

(Shutdown overnight under $\mathrm{SiCl} / \mathrm{H}_{2} \cdot$ )

$\begin{array}{llllll}31 & 67 & 0.18 & .14 .68 & 85.11 & 0.08 \\ 32 & 65 & 0.19 & 1.71 & 85.05 & 0.06 \\ 33 & 64 & 0.18 & 14.62 & 85.16 & 0.04 \\ 34 & 65 & 0.19 & 14.70 & 85.09 & 0.02 \\ 35 & 66 & 0.15 & 14.57 & 85.25 & 0.03\end{array}$

(Shutdown overnight under $\mathrm{SiCl}_{4} / \mathrm{H}_{2}$, )

$\begin{array}{llllll}36 & 63 & 0.14 & 14.48 & 85.30 & 0.08 \\ 37 & 65 & 0.18 & 14.67 & 85.09 & 0.06 \\ 38 & 66 & 0.19 & 14.21 & 85.56 & 0.04 \\ 39 & 63 & 0.17 & 14.59 & 85.21 & 0.03 \\ 40 & 64 & 0.18 & 14.74 & 85.04 & 0.04\end{array}$

$2 \mathrm{Cu} / \mathrm{Si}$ mass was cleaned by reacting with $\mathrm{HCl}$ at $330^{\circ}$ to collect 47 grams of crude. Then, temperature was raised to $550^{\circ}$ to start the hydrogenation experiment. 
TABLE II

Hydrogenation of $\mathrm{SiCl}_{4}$

\begin{tabular}{|c|c|c|c|c|c|c|c|c|c|}
\hline Sample \# & $\mathrm{H}_{2} / \mathrm{SiCl}_{4}$ & $\begin{array}{c}\text { Res -dence } \\
\text { T-me }\end{array}$ & $\mathrm{H}_{2}$ Flow & $\begin{array}{l}\text { Rota } \\
\text { Meter } \\
\end{array}$ & $\begin{array}{l}\text { Time } \\
\text { (Min) }\end{array}$ & $\begin{array}{l}\text { Weight } \\
\text { (g) }\end{array}$ & $\mathrm{g} / \mathrm{hr}$ & $\&$ tet & \& tri \\
\hline$Q-2669$ & 1.5 & 30 & 78.3 & 5.3 & 81 & 3.8 & 2.81 & 97.7 & 1.8 \\
\hline$Q-2670$ & 1.5 & 60 & 39.2 & 3.9 & 94 & 3 & 1.91 & 95.6 & 3.8 \\
\hline$Q-2671$ & 1.5 & 120 & 19.6 & 2.9 & 43 & 1.1 & 1.53 & 94.6 & 4.6 \\
\hline$Q-2672$ & 2.5 & 30 & 93.2 & 5.7 & 28 & 1.7 & 3.64 & 97.7 & 1.7 \\
\hline$Q-2673$ & 2.5 & 60 & 46.6 & 5 & 46 & 2.1 & 2.74 & 94.0 & 5.5 \\
\hline$Q-2674$ & 2.5 & 120 & 23.3 & 3.1 & 54 & .9 & 1 & 92.1 & 7.3 \\
\hline$Q-2675$ & 3.5 & 30 & 101.5 & 6 & 77 & 3.8 & 2.96 & 95.2 & 4.1 \\
\hline$Q-2676$ & 3.5 & 60 & 50.7 & 4.3 & 48 & 2.1 & 2.63 & 94.0 & 5.3 \\
\hline$Q-2677$ & 3.5 & 120 & 25.4 & 3.2 & 71 & 1.1 & .93 & 91.3 & 7.8 \\
\hline$Q-2678$ & 5 & 30 & 108.7 & 6.2 & 47 & 3.9 & 4.98 & 96.4 & 2.8 \\
\hline$Q-2679$ & 5 & 60 & 54.4 & 4.5 & 74 & 2 & 1.62 & 93.7 & 5.8 \\
\hline$Q-2680$ & 5 & $12 J$ & 27.2 & 3.4 & 155 & .9 & .35 & 95.1 & 4.4 \\
\hline
\end{tabular}

$\begin{array}{lll}\text { Initial silicon: } & \mathrm{Fe} & .34 \% \\ & \mathrm{Al} & .14 \\ \mathrm{Mu} & .04 \\ \text { Copper(18 of silicon): } & \mathrm{Cu} & 27.3 \\ & \mathrm{Cu}_{2} \mathrm{O} & 44.1 \\ & \mathrm{CuO} & 20.6 \\ \text { Exit tube coating: } & \mathrm{Si} & 60.0 \\ & \mathrm{Cu} & .70 \\ & \mathrm{Al} & 2.1 \\ & \mathrm{Fe} & 0.14\end{array}$



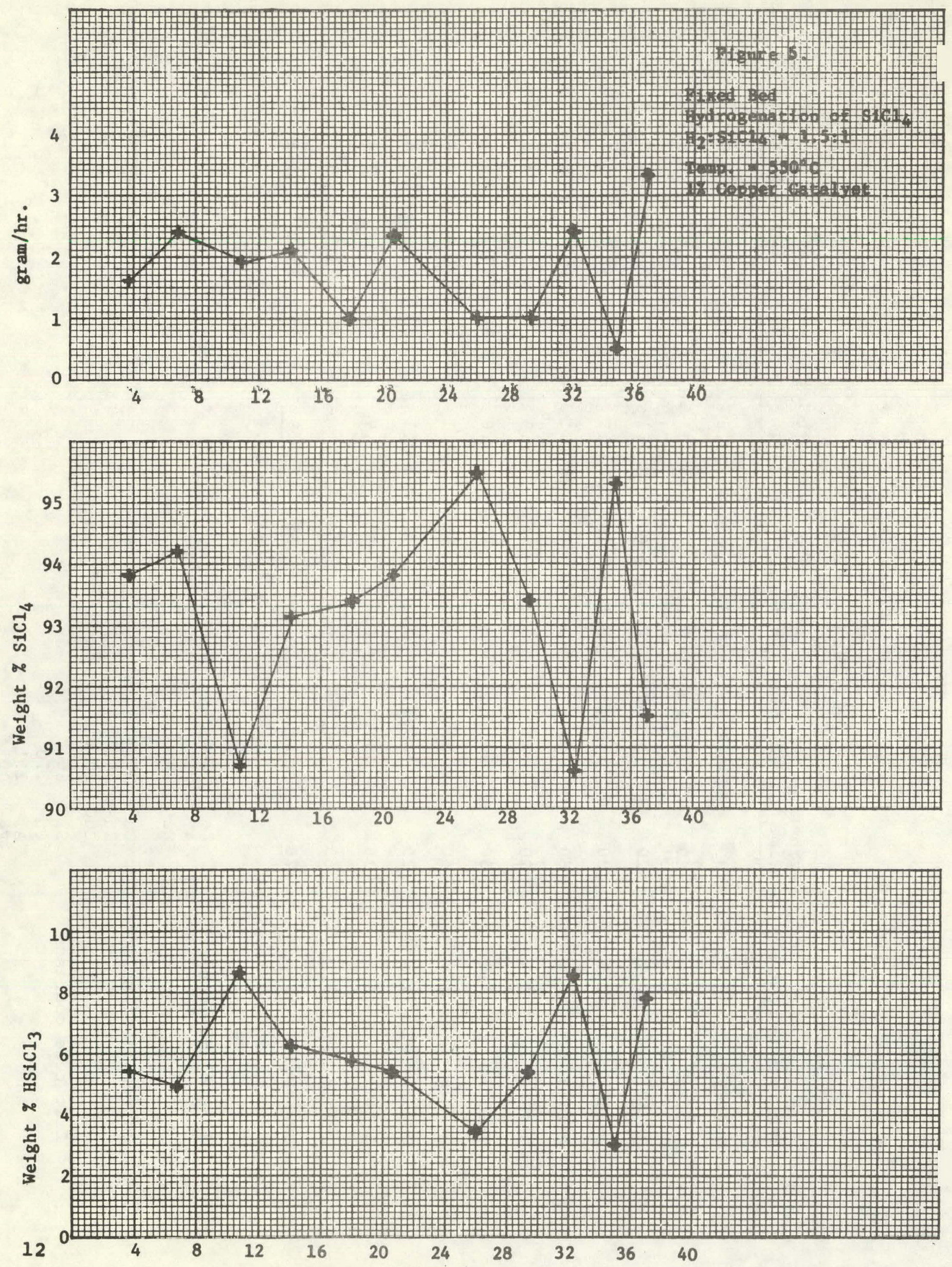


\section{TABLE II-a}

\section{HYDROGENATION OF SIClL TO HSICl 3 AT LOW REACTOR TEMPERATURES AT l: 1 SiCl $\mathrm{S}_{4} / \mathrm{H}_{2}$ RATIO}

\begin{tabular}{|c|c|c|c|c|c|c|c|c|}
\hline \multirow{2}{*}{$\begin{array}{l}\text { Experimental } \\
\text { Number } \\
\end{array}$} & \multirow{2}{*}{$\begin{array}{l}\text { Reactor } \\
\text { Temperature } \\
{ }^{\circ} \mathrm{C} \\
\end{array}$} & \multirow{2}{*}{$\begin{array}{l}\text { Hydrogen } \\
\text { Feedrate } \\
\text { cc/Minute }\end{array}$} & \multirow{2}{*}{$\begin{array}{c}\mathrm{SiCl}_{4} \\
\text { Feedrate } \\
\text { g/Ninute }\end{array}$} & \multirow{2}{*}{$\begin{array}{l}\text { Residence } \\
\text { Time (1) } \\
\text { Second } \\
\end{array}$} & \multicolumn{4}{|c|}{ Product Composition, Mole $\frac{}{6}$} \\
\hline & & & & & $\mathrm{H}_{2} \mathrm{SiCl}_{2}$ & $\mathrm{HSiCl}_{3}$ & $\mathrm{SiCl}_{4}$ & Heavies \\
\hline 1 & 500 & 220 & 1.54 & 10.2 & 0.12 & 13.37 & 86.10 & 0.41 \\
\hline 2 & 500 & 80 & 0.56 & 28.0 & 0.19 & 13.81 & 85.57 & 0.42 \\
\hline 3 & 450 & 250 & 1.76 & 9.6 & 0.14 & 10.44 & 89.30 & 0.13 \\
\hline 4 & 450 & 80 & 0.56 & 30.0 & 0.15 & 13.71 & 86.06 & 0.08 \\
\hline 5 & 450 & 40 & 0.28 & 60.0 & 0.13 & 14.04 & 85.57 & 0.26 \\
\hline 6 & 400 & 250 & 1.76 & 10.3 & 0.04 & 5.08 & 94.80 & 0.08 \\
\hline$\underset{\omega}{\omega}$ & 400 & 80 & 0.56 & 32.2 & 0.08 & 9.44 & 90.46 & 0.03 \\
\hline B & 400 & 40 & 0.28 & 64.3 & 0.10 & 11.95 & 87.89 & 0.06 \\
\hline
\end{tabular}

(1) Based on Empty Reactor 
The $\mathrm{HSiCl}_{3} y$ ield (13.7\%) at 30 seconds residence time was essentially the same as the $\mathrm{HSiCl}_{3}$ yield (14\%) at 60 seconds. This data suggested that, at $450^{\circ}$, reaction (1) reached equilibrium in about 30 seconds. On the other hand, experiments No. 6, 7, and 8 in Table II were carried out at $400^{\circ}$. As the yield of $\mathrm{HSiCl}_{3}$ (11.9\%) indicated, reaction (1) did not reach equilibrium with residence time up to 64 seconds. The equilibrium composition ( $14 \% \mathrm{HSiCl}_{3}$ ) at $450^{\circ}$ in experiment 5, Table II was essentially the same as those at higher reaction temperatures. Thus, reaction temperature greatly affected the rate of reaction, but not the equilibrium composition. In summary, the rate of the hydrogenation reaction in a fluidized bed reactor at atmospheric pressure ranged from a low of a few seconds at $550^{\circ}$ and $600^{\circ}$ to about 10 seconds at $500^{\circ}, 30$ seconds at $450^{\circ}$ and over 64 seconds at $400^{\circ}$. These reaction rates were based on a silicon particle size distribution of approximately $65 \times 150$ mesh (230 x 102 microns).

Earler work on the hydrogenation of $\mathrm{SiCl}_{4}$ by E.O. Brimm indicated an equilibrium reaction for the hydrogenation of $\mathrm{SiCl}_{4}$ to $\mathrm{HSiCl}_{3}$ in the presence of a Cu/Si contact mass.

$$
3 \mathrm{SiCl}_{4}+2 \mathrm{H}_{2}+\mathrm{Si} \stackrel{\mathrm{Cu}}{\rightleftarrows} 4 \mathrm{HSiCl}_{3}
$$

The purpose of studying the hydrogenation of $\mathrm{HSiCl}_{3}$ over a $\mathrm{Cu} / \mathrm{Si}$ contact mass was to collect data on the reversed reaction as represented in Equation (1) in an attempt to understand the mechanism of the hydrogenation reaction. Furthermore, the hydrogenation of $\mathrm{HSiCl}_{3}$ was carried out at reaction temperature range much lower than those of the $\mathrm{SiCl}_{4}$ hydrogenation previously studied in an attempt to synthesized $\mathrm{H}_{2} \mathrm{SiCl}_{2}$ (Equation 2).

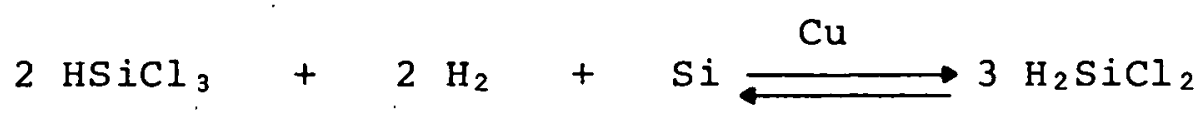

Although previous work by E. O. Brimm had shown no significant yield of $\mathrm{H}_{2} \mathrm{SiCl}_{2}$. when $\mathrm{SiCl}_{4}$ was replaced with $\mathrm{HSiCl}_{3}$ in his hydrogenation studies, the potential process advantage as represented by Equation (2) was tremendous. For example, it would combine the best of the hydrogenation reaction (Equation 1) and the dichlorosilane synthesis (Equation 3) in one step.

$$
2 \mathrm{HCl}+\mathrm{Si} \stackrel{\mathrm{Cu}}{\longrightarrow} \mathrm{H}_{2} \mathrm{SiCl}_{2}
$$


Furthermore, the recycle of $\mathrm{SiCl}_{4}$ and $\mathrm{HCl}$ as well as the step on the disproportionation of $\mathrm{HSiCl}_{3}$ to $\mathrm{H}_{2} \mathrm{SiCl}_{2}$ would be eliminated. Thus, it was worthy of the effort of a few experiments.

The hydrogenation of $\mathrm{HSiCl}_{3}$ was carried out in the same apparatus for the hydrogenation of $\mathrm{SiCl}_{4} \cdot \mathrm{HSiCl}_{3}$ and $\mathrm{H}_{2}$ were fed in a $1: 1$ molar ratio into a bed of Cu/Si mass $(200 \mathrm{~g}$, 1 wt. $\% \mathrm{Cu}$ ) in a one-inch diameter vycor reactor. The feed stream was obtained by dispersing $250 \mathrm{cc} / \mathrm{minute}$ of $\mathrm{H}_{2}$ gas into a liquid column of $\mathrm{HSiCl}_{3}$ maintained at $13.1^{\circ} \mathrm{C}$. The vapor pressure of $\mathrm{HSiCl}_{3}$ at $13.1^{\circ}$ was $380 \mathrm{~mm} \mathrm{Hg}$ which gave a $1: 1$ ratio of $\mathrm{HSiCl}_{3}$ to $\mathrm{H}_{2}$ at atmospheric pressure. A series of experiments were carried out at temperatures ranging from $325^{\circ}$ to $500^{\circ} \mathrm{C}$. The composition of the reaction products were analyzed by gas-liquid partition chromatography (glpc). Results were summarized in Table III. Data in Table III showed that the hydrogenation of $\mathrm{HSiCl}_{3}$ at $500^{\circ}$ (Experiment Number 1) resulted in $0.35 \% \mathrm{H}_{2} \mathrm{SiCl}_{2}, 21.5 \% \mathrm{HSiCl}_{3}$ and $76.2 \% \mathrm{SiCl}_{4}$. On the other hand, the hydrogenation of a $1: 1$ mixture of $\mathrm{SiCl}_{4}: \mathrm{H}_{2}$ at $500^{\circ}$ gave about $14 \% \mathrm{HSiCl}_{3}$ and $86 \% \mathrm{SiCl}_{4}$ as previously reported. Thus, the hydrogenation of $\mathrm{HSiCl}_{3}$ at $500^{\circ}$ gave no significant yield of $\mathrm{H}_{2} \mathrm{SiCl}_{2}$ and the product composition essentially indicated what one would expect for the reversed reaction as represented by Equation (1). As the reaction temperature was lowered from $500^{\circ}$ to $325^{\circ}$, data in Table III showed a rapid drop off in $\mathrm{SiCl}_{4}$ yield. Unfortunately, the yield of $\mathrm{H}_{2} \mathrm{SiCl}_{2}$ which reached a maximum of $1.8 \%$ was too small to be useful. The steady lowering of $\mathrm{SiCl}_{4}$ yield at lower reaction temperature suggested that higher $\mathrm{HSiCl}_{3}$ yield at lower reactor temperatures for the hydrogenation of $\mathrm{SiCl}_{4}$ might be plausible. However, it should be pointed out that the composition of product mixtures in Table III at temperature below $450^{\circ}$ was far from the composition of an equilibrium mixture, since the rate of reaction dropped off rapidly with lowering reaction temperatures. Experiment Number 8 in Table I showed the effect of replacing hydrogen with an inert gas, helium. The $\mathrm{SiCl}_{4}$ yield increased further still as would be expected since the partial pressure of hydrogen was reduced.

\section{Hydrogenation Reactor Design}

Based on the poor static bed results a fluid bed reactor was designed to study the hydrogenation of silicon tetrachloride (STC) to trichlorosilane (TCS) using a copper catalyst. The design criteria were:

1. Nominal 10 second superficial residence time

2. $\mathrm{H}_{2}: \mathrm{SiCl}_{4}$ ratio $2: 1$

3. Maximum pressure $\leq 1000 \mathrm{psi}$

4. Temperature $\leq 550^{\circ} \mathrm{C}$

5. Expected Throughput $7 \mathrm{~kg} / \mathrm{hr}$

6. Silicon particle size $<500$ micron 


\section{TABLE III}

SUMMARY OF DATE ON THE HIDROGENATION DF HSICl, IN A FLUIDIZED BED OF CU/SI MASS

\section{Experimental Flowrate Feedrate}

Hydrogen $\mathrm{HSiCl}_{3}$ Number

cc/Minut

gm, Minate

Mclar

Ratio

$\underline{\mathrm{H}_{2} / \mathrm{HSiCl}_{3}}$

(Purity of Starting $\mathrm{HSiCl}_{3}$ :

$\begin{array}{ccc}1 & 250 & 1.40 \\ 2 & 250 & 1.40 \\ 3 & 250 & 1.40 \\ 5 & 250 & i .40 \\ 6 & 250 & 1.40 \\ 7 & 250 & 1.40 \\ 8 & 250 & 1.40 \\ & * & 1.40\end{array}$

* $250 \mathrm{cc} / \mathrm{minute}$ of helium instead of hydrogen.
Reactor

Temperature ${ }^{\circ} \mathrm{C}$

1.0
1.0
1.0
1.0
1.0
1.0
1.0
1.0

500

450

400

375

350

325

500

500
Product Composition, Mole o $\underline{\mathrm{H}_{2} \mathrm{SiCl}_{2}} \underline{\mathrm{HSiCl}_{3}} \underline{\mathrm{SiCl}_{4}}$ Heavies

$\begin{array}{llll}0.26 & 99.49 & 0.19 & 0.06\end{array}$

$\begin{array}{llll}0.35 & 21.54 & 76.19 & 1.93\end{array}$

$\begin{array}{llll}0.52 & 30.35 & 68.79 & 0.35\end{array}$

$\begin{array}{llll}1.70 & 74.50 & 23.69 & 0.12\end{array}$

$\begin{array}{llll}1.81 & 87.01 & 11.17 & 0.02\end{array}$

$\begin{array}{llll}1.55 & 94.74 & 3.65 & 0.06\end{array}$

$\begin{array}{llll}1.21 & 96.63 & 2.02 & 0.13\end{array}$

$\begin{array}{llll}1.67 & 20.10 & 77.85 & 0.38\end{array}$

$\begin{array}{llll}0.07 & 10.19 & 89.66 & 0.07\end{array}$ 
In order to add make up silicon, the bottom fluid bed inlet would be a cone shape where the bed would be supported on the incoming gas jet. Based on that criteria, an entrance cone half angle was calculated from:

$$
\cot \gamma=10.4\left[\begin{array}{ll}
e_{p} & a_{p} \\
e_{f} & a_{0}
\end{array}\right]^{-3}
$$

Where $d_{p}=150 \times 10^{-6} \mathrm{~cm}$ (smallest silicon particle)

$\mathrm{d}_{\mathrm{O}}=.95 \mathrm{~cm}$ (entrance pipe diameter)
$\mathrm{e}_{\mathrm{p}}=2.42 \mathrm{gm} / \mathrm{cm}^{3}$ density of silicon
$\mathrm{e}_{\mathrm{f}}=.00877 \mathrm{gm} / \mathrm{cm}^{3}$ density of $\mathrm{H}_{2} / \mathrm{SiCl}_{4} \mathrm{mixture}$
$\varnothing 0.55^{\circ}$ or a total cone angle of $17^{\circ}$

In order to calculate the height of the reactor, the minimum fluidization velocity was needed. An expression for this is given by Kuni and Levenspiel ${ }^{2}$

$$
\frac{1.75}{\varnothing_{g} e_{m f}} 3\left(\frac{D_{p} U_{m f} e_{g}}{\mu}\right)^{2}+\frac{150\left(1-e_{m f}\right)}{\varnothing^{2} \cdot e_{m f}} 3\left(\frac{a_{p} U_{e}}{\mu}\right)=\frac{a^{3} e_{g}\left(e_{g}-e_{g}\right) g}{\mu^{2}}
$$

However, the viscosity, $\mu$, of hydrogen-sTC mixtures has not been measured and could vary considerably from that found by the normal mixture rules. The method of Buddenberg and $W_{i l} \mathrm{k}^{3}$ was used to give a value of 0.0300 centipoise at $500^{\circ} \mathrm{C}$ for a $2: 1$ molar ratio of $\mathrm{H}_{2}: \mathrm{SiCl}_{4}$. From this value, the properties of the silicon metal and the equation above, the minimum fluidization velocity of $2.1 \mathrm{~cm} / \mathrm{sec}$ was calculated. The total reactor height is the sum of the expanded bed and the transport disengaging height. These are summarized in Table IV.

To enable the reactor to be disassembled for cleaning, withstand temperature cycling, and still maintain a good seal against the high pressure hydrogen, all metalic connections are desirable such as Grayloc or Haskel. The heating unit will consist of four ceramic encapsulated heating units surrounding the reactor and controlled with a powerstat. The feed will be preheated by a coil passing through a heater with control achieved by by-passing an amount to give the required inlet temperature. The ancillary condensers, feed pump, instruments, etc. are for the most part already on hand and some have been mounted. 


\section{HYDROCENATION REACTOR DESIGN, SUMMARY}

\begin{tabular}{|c|c|}
\hline Conditions: & 150 psia ; $500^{\circ} \mathrm{C}$ \\
\hline Gas residence time: & 10 seconds \\
\hline $\mathrm{H}_{2}: \mathrm{SiCl}_{4}$ ratio & $2: 1$ \\
\hline Gas density & $.547 \mathrm{ib} / \mathrm{ft}^{3} \quad .0087 \% \mathrm{gt} / \mathrm{cc}$ \\
\hline Gas viscosity & $.0300 \mathrm{cps}$ \\
\hline Solid density & $137 \mathrm{lb} / \mathrm{ft}^{3} ; 2.2 \mathrm{sp}$ \\
\hline Average particle & $(65 \times 150$ mesh $)=1 \% 0 \mu$ \\
\hline Estimated shape factor & .67 \\
\hline Estimated voidage at minimum fluidization $=$ & .56 \\
\hline Estimated minimum fluidization velocity = & $2.1 \mathrm{~cm} / \mathrm{sec}$ \\
\hline At $2 \times \mathrm{U}_{\mathrm{mf}}=$ & $4.2 \mathrm{~cm} / \mathrm{sec}$ or $.14 \mathrm{ft}$ sec \\
\hline Total reactor height & $190 \mathrm{~cm}$ \\
\hline Diameter (nominal $3 "$ sched. 40 pipe) & $7.62 \mathrm{~cm}$ \\
\hline Entrance cone angle & $17^{\circ}$ \\
\hline
\end{tabular}


4. Maxi-Plant Design

The original process flow scheme for a "maxi-plant" for converting TCS to $\mathrm{SiH}_{4}$ utilized three distillation columns, two redistribution reactors and a adsorber/stripper enrichment section with final chlorosilane removal accomplished using a carbon trap. This basically was an integration of the DCS commercial production scheme into the silane mini-plant in that both pure TCS and DCS were isolated intermediates. An alternate process configuration has been outlined which accomplishes the same conversion but which utilizes fewer items of equipment and requires lower energy input. The revised flow scheme is shown in Figure 6 . The feed to this process can be either pure TCS as shown entering surge tank T-2, or it can be the TCS/STC mixture produced by hydrogenation of the STC. In this case, the feed would enter the DCS/TCS still (S-2) directly. A resin reactor is used to convert high purity TCS from the silane mini-plant to a mixture of Di,. Tri, and Tetrachlorosilanes. A still separates out the STC while the DCS/TCS distillate flows to the silane still in the mini-plant. Here the TCS is removed as distilland for recycle to the first resin reactor (along with makeup TCS). The DCS distillate flows through a second resin reactor which results in the formation of silane (and other chlorosilanes before returning to the silane still). The silane product leaves in equilibrium with the distillate as a non-condensed vapor through a partial condenser. The purity of the crude silane at this point should be as was discussed earlier, about 978 . A carbon trap could remove the last traces of chlorosilanes.

Heat balance calculations are incomplete, but it is certain that the thermal requirements will be lower than the original case due to the lower number of moles of material required to be vaporized.

\section{Reaction Mechanism Studies}

Laboratory experiments were planned to study the mechanism of the disproportionation reaction of chlorohydrosilanes to $\mathrm{SiH}_{4}$ and the nature of the A-2l resin catalyst. One school of thought was that the amine hydrochloride was the active catalyst in the redistribution of $\mathrm{SiH}$ and $\mathrm{SiCl}$ linkages. In the present study on the disproportionation of $\mathrm{H}_{2} \mathrm{SiCl}_{2}$ to $\mathrm{SiH}_{4}$, there was one piece of evidence ${ }^{l}$ which showed an enhanced reaction rate after the $A-21$ resin bed was treated with $\mathrm{HCl}$ gas. To further study this problem, experiments with deuterium-labeled compounds might provide useful information on the reaction mechanism. For example, using deuterium chloride, DCl, instead of $\mathrm{HCl}$ to "activate" the A-2l resin, one could follow the deuterium-containing end products, if any, which 


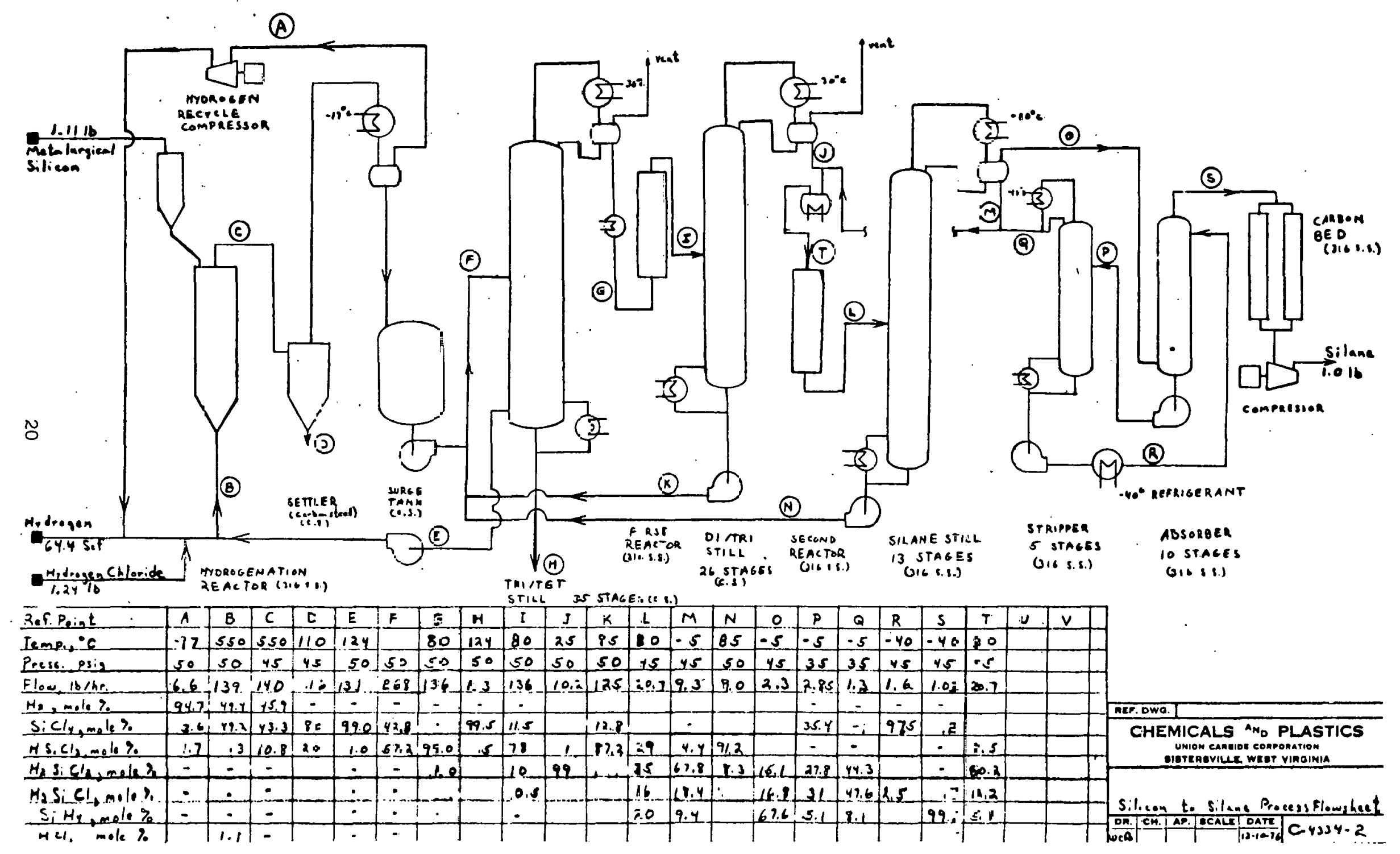

Figure 6 Silane Nax--Plant Proposed Flow Sheet 
might provide useful information on the nature of the catalyst sites. Kinetic isotope effect would be another area of investigation which could provide useful data on the mechanism of the disproportionation reaction. Studies on the relative rate of disproportionation of $\mathrm{HSiCl}_{3}$ versus $\mathrm{DSiCl}_{3}$ could provide answers on the nature of the activation complex and other reaction intermediate species. To carry out these experiments, an analytical method would be required for the quantitative measurements of samples containing, e.g., $\mathrm{HCl}, \mathrm{DCl}_{1} \mathrm{HSiCl}_{3}, \mathrm{DSiCl}_{3}$, and $\mathrm{SiCl}_{4}$, etc.

\section{a. Direct Reaction of $\mathrm{HCl}$ and $\mathrm{DCl}$ With Si Metal}

A quantity of deuterium - labeled $\mathrm{DSiCl}_{3}$ was prepared for kinetic isotope effect studies. The synthesis was made by the direct reaction of $\mathrm{DCl}$ with $\mathrm{Si}$ metal at $320^{\circ}$ in a fluidized bed reactor. ${ }^{2}$ It would be interesting to compare the $\mathrm{HCl}+\mathrm{Si}$ reaction with the $\mathrm{DCl}+\mathrm{Si}$ reaction to see if whether there was a significant isotope effect. Hopefully, these data would provide useful informations to understand the mechanism of the $\mathrm{HCl}+\mathrm{Si}$ reaction itself, since the direct synthesis of $\mathrm{HSiCl}_{3}$ is an important commercial process. The $\mathrm{HCl}+\mathrm{Si}$ reaction and the $\mathrm{DCl}+\mathrm{Si}$ reaction were carried out separately in the same apparatus with the same lot of $65 \times 150$ mesh Si metal under the same experimental condition. The feedrates of $\mathrm{HCl}$ and $\mathrm{DCl}$ were both left at $1200 \mathrm{cc} / \mathrm{minute}$ at $22^{\circ}$ so as to convert the same amount of $\mathrm{Si}$ metal in every hour. The apparatus was the same one used for the dichlorosilane synthesis. ${ }^{3}$ The 1.25-inch diameter fluidized bed reactor was charged 300 grams of $\mathrm{Si}$ metal. The reactor was heated to $320^{\circ}$ under nitrogen. Then, it was replaced with $\mathrm{HCl}$ gas at $1200 \mathrm{cc} / \mathrm{minute.} \mathrm{Samples} \mathrm{of} \mathrm{the}$ HSiCl ${ }_{3}$ crude were collected every hour, weighed and analyzed. The $\mathrm{HCl}+\mathrm{Si}$ reaction was carried out first for a total of seven hours. Results of this experiment were summarized in Table V. Data in Table $V$ showed the composition of the chlorosilane products at various percent conversion of the $S i$ mass bed. The major products of the $\mathrm{HCl}+\mathrm{Si}$ reaction were $\mathrm{HSiCl}_{3}$. As the reaction progressed, the yield of $\mathrm{SiCl}_{4}$ gradually increased from $5 \%$ to about 11 \% at the expense of $\mathrm{HSiCl}_{3}$. This phenomenon was typical of the $\mathrm{HCl}+\mathrm{Si}$ reaction, which was most likely due to the gradual change of the solid surface characteristics. As the Si metal was reacted away, the smooth solid surface became highly pitted resulting a much larger surface area. Then, as more $\mathrm{si}$ was reacted, metal halide impurities began to accumulate. As the reaction progressed further, these variables became stabilized. This was then reflected in a steady state $\mathrm{SiCl}_{4}$ yield which leveled off at about $11 \%$ as shown in Table $\mathrm{V}$.

Similarly, the $\mathrm{DCl}+\mathrm{Si}$ reaction was carried out in the same manner. The apparatus was cleaned in a $\mathrm{KOH}$ bath to remove trace of $\mathrm{SiH}$ which might be present. Then, the reactor was recharged with 300 grams of the same Si metal used in the $\mathrm{HCl}+\mathrm{Si}$ reaction. The reaction was carried out at $320^{\circ}$ for four hours. 
TABLE V

\section{DIRECT REACTION OF HCl GAS KITH Si METAL AT $320^{\circ}$, ATMOSPHERIC PRESSURE}

\begin{tabular}{|c|c|c|c|c|c|c|c|}
\hline \multirow{2}{*}{$\begin{array}{l}\text { Experimental } \\
\text { Number }\end{array}$} & \multirow{2}{*}{$\begin{array}{l}\text { HCl } \\
\text { Feedrate } \\
\text { cC/Minute } \\
\end{array}$} & \multirow{2}{*}{$\begin{array}{c}\text { Trichlorosilane } \\
\text { Crude } \\
\text { Gram/Hour } \\
\end{array}$} & \multirow{2}{*}{$\begin{array}{c}\text { Silicon Mass } \\
\text { Converted } \\
8 \\
\end{array}$} & \multicolumn{4}{|c|}{ Froduct Composition, Mole 8} \\
\hline & & & & $\mathrm{H}_{2} \mathrm{SiCl}_{2}$ & $\mathrm{HSiCl}_{3}$ & $\mathrm{SiCl}_{4}$ & Heavies \\
\hline 1 & 1200 & $114: 1$ & 7.68 & 0.12 & 94.78 & 5.06 & 0.05 \\
\hline 2 & 1200 & 130.8 & 16.5 & 0.20 & 91.88 & 7.91 & 0.02 \\
\hline 3 & 1200 & 126.0 & 25.0 & 0.34 & 84.95 & 14.69 & 0.02 \\
\hline 4 & 1200 & 132.4 & 33.9 & 0.17 & 89.57 & 10.24 & 0.02 \\
\hline 5 & 1200 & 128.0 & 42.5 & 0.14 & 88.84 & 11.00 & 0.03 \\
\hline 6 & 1200 & 127.3 & 51.1 & 0.21 & 88.42 & 11.35 & 0.02 \\
\hline 7 & 1200 & 119.2 & 59.1 & 0.09 & 88.80 & 11.06 & 0.05 \\
\hline
\end{tabular}

1 Sample coliected every hour. 
TABLE VI

DIRECT REACTION OF DCI GAS WITH SI METAL AT $320^{\circ}$, ATMOSPHERIC PRESSURE

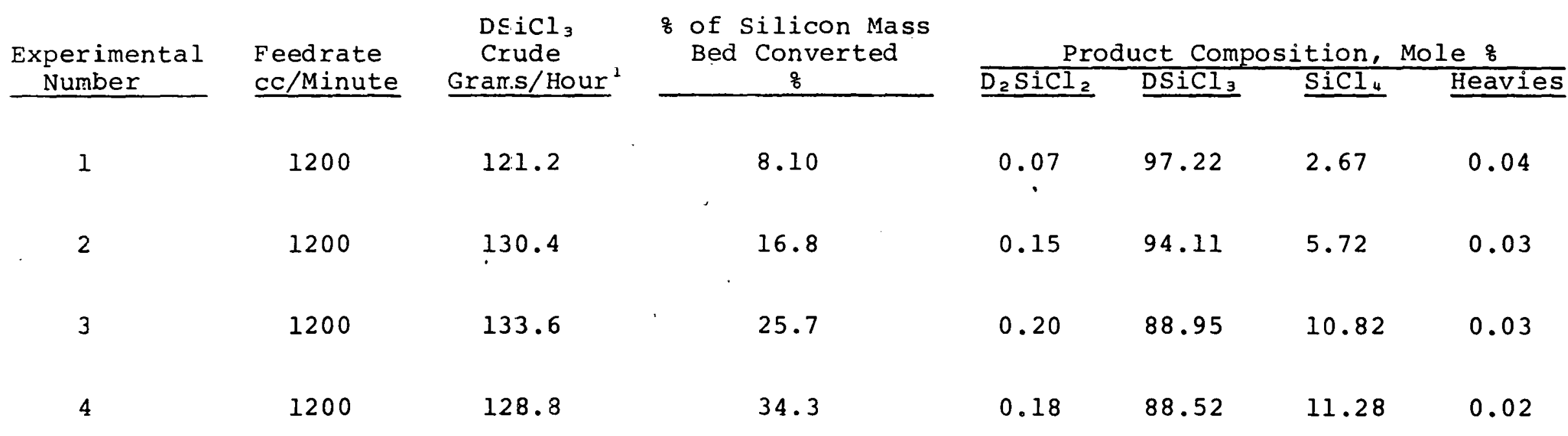

$\stackrel{N}{\omega}$

1 Sample collected every hour. 
Results were summarized in Table VI. Analysis of the product composition at various percent conversion of the $\mathrm{Si}$ mass bed showed similar results with the $\mathrm{SiCl}_{4}$ yield gradually increased from 2.67\% to about $11 \%$ at the expense of $\mathrm{DSiCl}_{3}$. Comparison with data in Table $V$ with that of Table VI showed that the yield of $\mathrm{SiCl}_{4}$ in the $\mathrm{DCl}+\mathrm{Si}$ reaction was significantly lower than those of the $\mathrm{HCl}+\mathrm{Si}$ reaction in the first three hours, i.e., $2.67 \%, 5.72 \%$, and $10.82 \%$ versus $5.06 \%, 7.91 \%$ and $14.69 \%$ respectively. However, the fourth hour sample showed a reversed trend, namely, $11.28 \%$ versus $10.24 \%$. Overall, one might conclude that the $\mathrm{DCl}+\mathrm{Si}$ reaction produced less $\mathrm{SiCl}_{4}$ than that of the $\mathrm{HCl}+\mathrm{Si}$ reaction. Unfortunately, the limited amount of DCl available allowed only four hours of reaction. At this point, the reaction was still in an unsteady state. Consequently, not much information could be derived from these few hours of reactions.

\section{b. Material Balance}

1) $\mathrm{HCl}+\mathrm{Si}$ Reaction

A total of 881.3 grams $\mathrm{HSiCl}_{3}$ crude was collected in the $\mathrm{HCl}+\mathrm{Si}$ reaction. The $\mathrm{Si}$ content was calculated to be

$$
\frac{28.06}{129} \times 881.3=177.9 \mathrm{~g} \mathrm{si}
$$

based on the average molecular weight (90\% $\left.\mathrm{HSiCl}_{3}, 10 \% \mathrm{SiCl}_{4}\right)$ of 139 for the trichlorosilane crude. The spent Si mass weighed 119.2 grams which corresponded to $300-119.2=180.8$ grams $\mathrm{Si}$ metal consumed. Thus, material balance for Si was

$$
\frac{177.9}{180.8} \times \quad 100=98.4 \%
$$

2) $\mathrm{DCl}+\mathrm{Si}$ Reaction

A total of 517.7 grams of usicl 3 crude was collected. Based on the average molecular weight of 140 for the $\mathrm{DSiCl}_{3}$ crude, the $\mathrm{Si}$ content in the chlorosilanes was

$$
\frac{28.06}{140} \times 517.7=103.0 \mathrm{~g}
$$

The spent $\mathrm{Si}$ mass weighed 195 grams which corresponded to $300-195=$ 105 grams of $\mathrm{Si}$ metal consumed. Thus, material balance for.Si was

$$
\frac{103.8}{105} \times 100=98.8 \%
$$




\section{c. Fractional: Distillation of $\mathrm{DS}_{\mathrm{iCl}} \mathrm{Cl}_{3}$ Crude}

A combined hourly product mixtures of $\mathrm{DSiCl}_{3}$ crude gave a total of 514 grams. It was fractionally distilled through a 3-foot, 0.75-inch I.D., 1/4-inch glass helices-packed column. Three fractions were collected.

Fraction 1 weighed 234 grams and glpc analysis gave $0.23 \% \mathrm{D}_{2} \mathrm{SiCl}_{2}, 99.44 \% \mathrm{DSiCl}_{3}$ and $0.31 \%$ $\mathrm{SiCl}_{4}$.

Fraction 2 weighed 104 grams and glpc analysis gave $0.04 \% \mathrm{D}_{2} \mathrm{SiCl}_{2}, 99.06 \% \mathrm{DSiCl}_{3}$ and $0.88 \%$

$\mathrm{SiCl}_{4}$.

Fraction 3102 grams was mixture of $\mathrm{DSiCl}_{3}$ and $\mathrm{SiCl}_{4}$. Residue weighed 23 grams.

At about a third of the way during the distillation, a high purity sample of $\mathrm{DSiCl}_{3}(47 \mathrm{grams})$ was collected at boiling point $32.0^{\circ} \mathrm{C}$. Gas-liquid partition chromatography (glpc) analysis gave $0.056 \mathrm{D}_{2} \mathrm{SiCl}_{2}, 99.82 \% \mathrm{DSiCl}_{3}$ and $0.13 \% \mathrm{SiCl}_{4}$. This sample of $\mathrm{DSiCl}_{3}$ served as a standard reference for the calibration of analytical instruments.

\section{d. Apparatus and Analytical Instrumentation}

A number of analytical methods were considered. Gasliquid partition chromatography, glpc, remained the method of choice for the analysis of multi-components of different boiling points, e.g., $\mathrm{HCl}, \mathrm{H}_{2} \mathrm{SiCl}_{2}, \mathrm{HSiCl}_{3}$, and $\mathrm{SiCl}_{4}$, etc. Analysis of $\mathrm{HSiCl}_{3}$ and $\mathrm{DSiCl}_{3}$ by glpc would present difficulties for their very close range of boiling point and molecular weight. The best method appeared to be Infrared Spectroscopy. Preliminary investigation showed that the $\mathrm{SiH}$ absorption band occurred at $2250 \mathrm{~cm}^{-1}$ (4.4 microns) whereas the SiD absorption band occurred at $1640 \mathrm{~cm}^{-1}$ (6.1 microns). The SiH and SiD absorption bands were far apart and did not interfere with each other. An apparatus was set up to provide quantitative measurements on the amount of samples which would be charged into the IR cell for infrared spectroscopic analysis. The apparatus was schematically shown in Figure 7. The standard gas IR cell was equipped with $\mathrm{KBr}$ windows with a $10 \mathrm{~cm}$ path. It was attached to a two-liter sample flask and to the vacuum mainfold. A sample of chlorosilane was weighed in the small 2 c.c. sample which was then attached to the sample flask as shown in Figure 7. The sample flask was evacuated. The chlorosilane sample was then injected and vaporized into the 2-l sample flask. The vapor pressure of chlorosilane was measured with the mercury manometer. Other reference standard, if needed, could be added in the same manner at this point. 
FIGURE 7 Apparatus In Quantitative Infrared

Specturecopec Cinalypis of $H S_{i} C_{3}$ and $D S_{i} C_{3}$

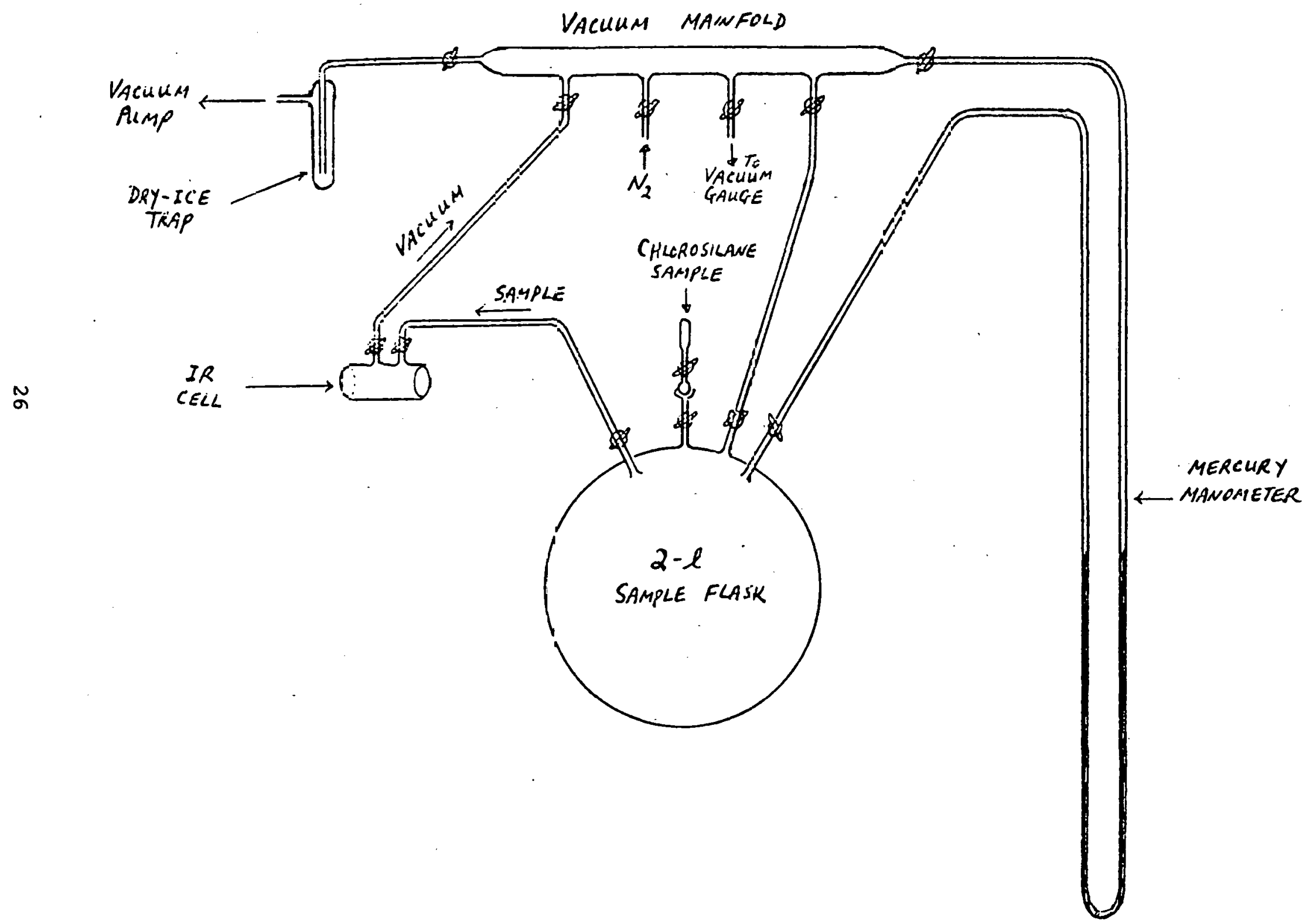


Then, dry nitrogen gas was introduced to bring the system to slightly above atmospheric pressure. The IR cell was evacuated and charged with the diluted gaseous sample to atmospheric pressure. The amount of chlorosilane sample in the IR cell could be readily calculated from the weight of the sample and from the pressurevolume relationship. The sample was scanned with a Beckman 4240 IR Spectrometer. Preliminary studies indicated that partial pressure of $\mathrm{HSiCl}_{3}$ in the diluted sample ranging from $5 \mathrm{~mm}$ to $50 \mathrm{~mm}$ Hg would be sufficient to cover the range of the IR instrument for the $\mathrm{SiH}$ analysis.

\section{e. Calibration of IR Instrument for $\mathrm{DSiCl}_{3}$}

The Infrared Spectrometer (Beckman IR 4240) was calibrated with standard samples of $\mathrm{HSiCl}_{3}$ and $\mathrm{DSiCl}_{3}$. The $10 \mathrm{~cm}$ gas sample cell was equipped with $\mathrm{KBr}$ windows. It was charged with known amounts of $\mathrm{HSiCl}_{3}$ and $\mathrm{DSiCl}_{3}$ in nitrogen. Samples of $\mathrm{HSiCl}_{3}$ were prepared in the IR cell and scanned with the IR Spectrometer at partial pressure of $\mathrm{HSiCl}_{3} 2.9,6.3,13.6$, and $29.4 \mathrm{mmHg}$ respectively. The percent absorbance was recorded for each sample. The SiH band in the infrared spectrum consisted of three peaks at 2264, 2254, and $2245 \mathrm{~cm}^{-1}$ respectively. The percent absorbance of each of these three peaks were plotted against $\mathrm{HSiCl}_{3}$ concentrations as shown in Figure 8. The calibration curve in Figure 8 showed that the intensities of the SiH absorption bands did not follow a linear relationship with concentrations as described by Beer's Law. Similarily, the IR instrument was calibrated with known samples of $\mathrm{DSiCl}_{3}$ at partial pressure of $0.5,1.1,2.3,5.0,10.0$, and $24.0 \mathrm{~mm} \mathrm{Hg}$ respectively. The percent absorbance of the SiD absorption bands was recorded for each sample. The SiD band in the IR spectrum consisted of three sharp peaks at 1649,1642 , and $1637 \mathrm{~cm}^{-1}$. A shoulder peak was also present at $1633 \mathrm{~cm}^{-1}$. The percent absorbance of these three sharp peaks were plotted against $\mathrm{DSiCl}_{3}$ concentration as shown in Figure 9. Data on Figure 9 showed that the SiD absorption intensities did not follow a linear relationship with concentrations either. A standard mixture of $0.225 \mathrm{~g} \mathrm{HSiCl}_{3}$ and $0.170 \mathrm{~g} \mathrm{DSiCl}_{3}$ was prepared. The whole sample mixture was vaporized and charged into the IR cell to give $13.7 \mathrm{~mm} \mathrm{Hg}$ partial pressure of $\mathrm{DSiCl}_{3}$. The standard mixture in the IR cell was scanned with the Beckman IR 4240 spectrometer. The absorbance of the three SiH absorption peaks was measured. The concentration of $\mathrm{HSiCl}_{3}$ was determined from the calibration curves in Figure 8. Three $\mathrm{HSiCl}_{3}$ concentrations were read from the calibration curves which corresponded to each of the three SiH absorption peaks. The average of these three measurements gave $14.1 \mathrm{~mm} \mathrm{Hg}$ of $\mathrm{HSiCl}_{3}$ in good agreement with the $13.7 \mathrm{~mm} \mathrm{Hg}$ figure by vapor pressure measurements. Similarily, the concentration of $\mathrm{DSiCl}_{3}$ was determined from the calibration curves in Figure 9 from the percent absorbance of the three SiD absorption peaks. The average readings gave $11.0 \mathrm{~mm} \mathrm{Hg}$ $\mathrm{DSiCl}_{3}$ in good agreement with the $11.5 \mathrm{~mm} \mathrm{Hg}$ figure by vapor pressure measurement. 
Figure 8 PLot of SiH absorbance versus HSICl CONCENTRATION (IO CM GAS CELL)

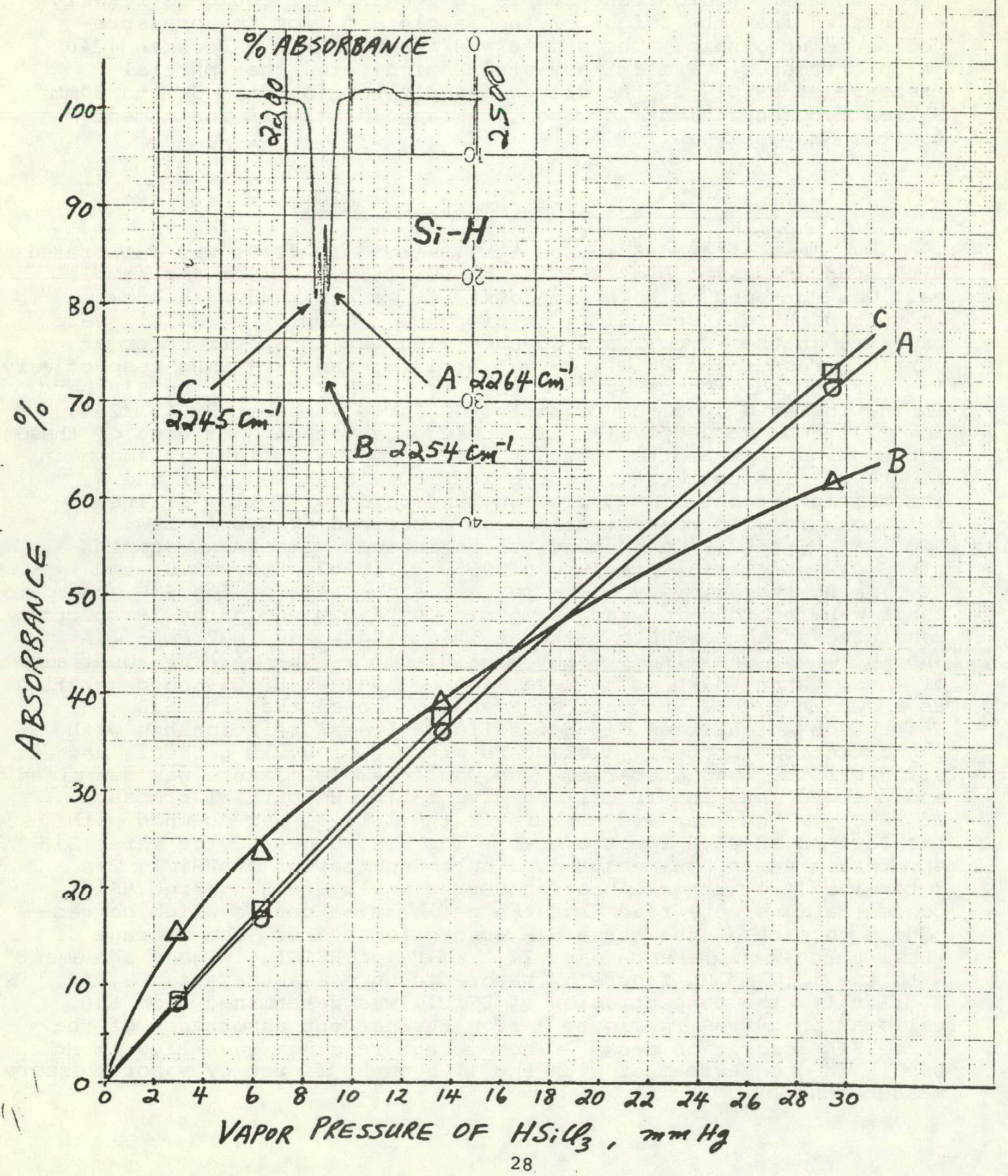


FIGURE 9 PLOT OF SID ABSORBANCE VERSUS $D S_{i} C_{3}$ CONLENTRATION ( $10 \mathrm{~cm}$ GAS (ELL)

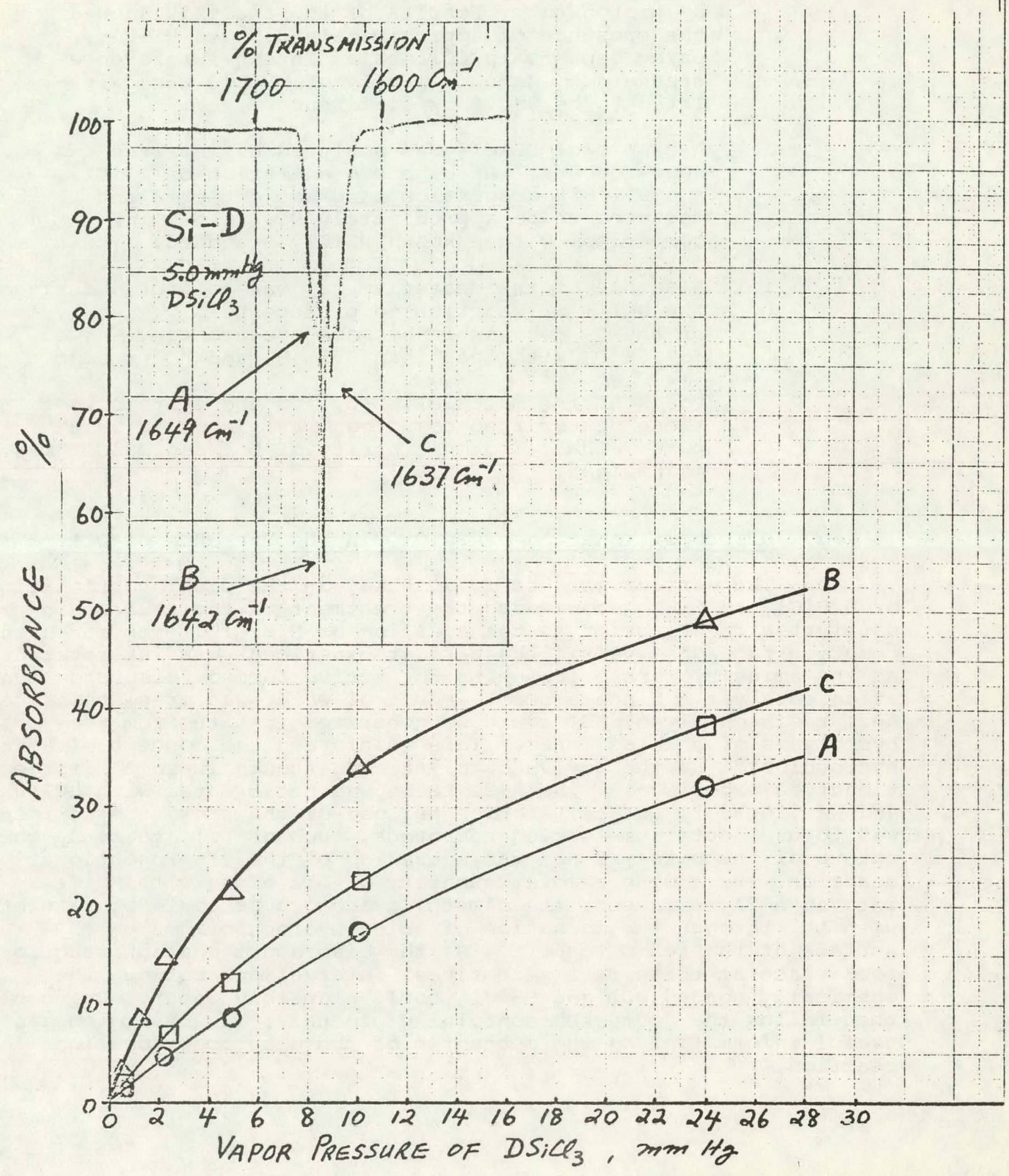


f. Summary of Analytical Results on DCl and $\mathrm{DSiCl}_{3}$

(i) Sample of purified $\mathrm{DSiCl}_{3}$ was sent for analysis by proton nmr. Results of the analysis showed the presence of approximately $0.3 \mathrm{wt} \% \mathrm{HSiCl}_{3}$, using benzene in $\mathrm{CCl}_{4}$ as an internal reference standard. Isotopic purity of $\mathrm{DSiCl}_{3}$ was calculated to be $99.7 \%$ by difference.

(ii) A sample of $\mathrm{DSiCl}_{3}$ was analyzed by infrared spectroscopy. At high concentration of $\mathrm{DSiCl}_{3}$, a small $\mathrm{SiH}$ absorption band was detected and measured to be approximately 0.4 mole $\%$ in comparison with a known IIGiCl $_{3}$ standard.

(iii) A sample of the deuterium gas was collected during the $\mathrm{DCl}+\mathrm{Si}$ reaction to produce $\mathrm{DSiCl}_{3}$. Analysis of the $\mathrm{D}_{2}$ gas sample by mass spectroscopy showed $+99.6 \% \mathrm{D}_{2}$ with less than $0.2 \% \mathrm{H}_{2}$ and HD present.

The starting material, $\mathrm{D}_{2} \mathrm{O}$, for the synthesis of these deuteriated compounds was listed as $99.8 \%$ pure. Thus, isotopic purity of $\mathrm{DCl}$ and $\mathrm{DSiCl}_{3}$ was llld inlained.

g. Disproportionation of $\mathrm{HSiCl}_{3}$ in the Presence of $\mathrm{DCl}$

The earlier work of C. J. Bakay on the disproportionation of $\mathrm{H}_{2} \mathrm{SiCl}_{2}$ to $\mathrm{SiH}_{4}$ recommended the treatment of the $\mathrm{A}-2 \mathrm{l}$ resin catalyst with $\mathrm{HCl}$ prior to the addition of $\mathrm{H}_{2} \mathrm{SiCl}_{2}$. The enhanced reaction rate observed in the earlier experiment was interpreted as the amine hydrochloride being the active form of disproportionation catalyst. Since a small amount of water was present in the A-2l resin catalyst, $\mathrm{HCl}$ could be generated in-situ from the hydrolysis of chlorosilanes. This reinforced the concept of amine hydrochloride as the active catalyst even though in some disproportionation experiments, the $\mathrm{A}-21$ resin was not treated with $\mathrm{HCl}$ gas and was found to be active. The purpose of the present experiment was to use deuterium-labeled compounds, such as DCl, to study the nature of the catalyst and the mechanism of the disproportionation reaction. By adding a molar quantity of $\mathrm{DCl}$ along with $\mathrm{HSiCl}_{3}$ into an A-2l resin bed, the dimethylamino qroups could be saturated with DCl through the formation of amine hydrochlorides on the surface of the resin support. As the disproportionation reaction took place at these catalytic sites, interactions between the chemically bonded $\mathrm{DCl}$ and $\mathrm{HSiCl}_{3}$ could plausibly occur. One could then follow the deuterium-containing products, if any, to obtain useful information on the mechanism of the disproportionation reaction. 
The disproportionation of $\mathrm{HSiCl}_{3}$ in the presence of $\mathrm{DCl}$ in a bed of A-21 resin catalyst was carried out in apparatus schematically shown in Figure 10. The reactor was charged with $40 \mathrm{~g}$ of $A-21$ resin. It was heated by hot water circulating through the condenser jacket from a constant temperature bath at $60^{\circ}$. Trichlorosilane was fed through a capillary flowmeter and was vaporized in the preheater. The $\mathrm{HSiCl}_{3}$ vapor and $\mathrm{DCl}$ gas was mixed at the top of the A-2I resin bed. The gaseous mixture flowed downward through the A-2l resin catalyst. The product mixture was passed through a Dry-Ice condenser. Product chlorosilanes were condensed and collected for analysis. Non-condensable gases would pass through a 3-way stopcock to either a gas burette which measured the gas flowrate or to disposal into the fume hood. All connecting tubes were heat-traced with an electric heater to keep the reaction mixture in the vapor state. A sample outlet between the reactor and the Dry-Ice condenser was connected to the in-line gas chromatograph which provided rapid analysis of the reaction mixtures as they came out of the reactor. A series of experiments was carried out at $60^{\circ}$ with various ratios of $\mathrm{HSiCl}_{3}$ to DCl. Results of these experiments were summarized in Table 7. Experiment No. 1 in Table 7 was carried out with no DCl added. The product composition was similar to what was observed in previous experiments on the vapor phase disproportionation of $\mathrm{HSiCl}_{3}{ }^{1}$ The major products were $\mathrm{H}_{2} \mathrm{SiCl}_{2}$ and $\mathrm{SiCl}_{4}$ with a small amount of $\mathrm{H}_{3} \mathrm{SiCl}$. Next, $\mathrm{DCl}$ was introduced into the reactor in about the same amount as $\mathrm{HSiCl}_{3}$. Data in Experiment No. 3 and No. 4 in Table 2 showed that the addition of $\mathrm{DCl}$ to the $\mathrm{A}-21$ resin bed along with $\mathrm{HSiCl}_{3}$ produced some surprising results. First of all, over $80 \%$ of the DCl added was consumed. Large amount of $\mathrm{SiCl}_{4}$ was produced while most of the SiH-containing chlorosilanes were destroyed. A non-condensable gas was generated and collected in the gas burette. Analysis of this gaseous product by mass spectroscopy showed that it contained mostly $\mathrm{H}_{2}, \mathrm{HD}, \mathrm{D}_{2}$ and small amounts of $\mathrm{HCl}$ and $\mathrm{DCl}$. The isotope ratio in the hydrogen gas was found to contain $8 \% \mathrm{H}_{2}, 80 \% \mathrm{Hn}$, and $72 \% \mathrm{D}_{2}$. Thus, it was apparent that the $\mathrm{SiH}$ linkages in the chlorohydrosilanes were rapidly cleaned by $\mathrm{DCl}$ in the presence of $\mathrm{A}-21$ resin catalyst. The major reaction appeared to be the well-known acid-catalyzed SiH cleavage to form hydrogen gas, namely nucleophilic attack of $\mathrm{Cl}$ on silicon with the elimination of $\mathrm{SiH}$ as hydrogen (Equation 4 ).

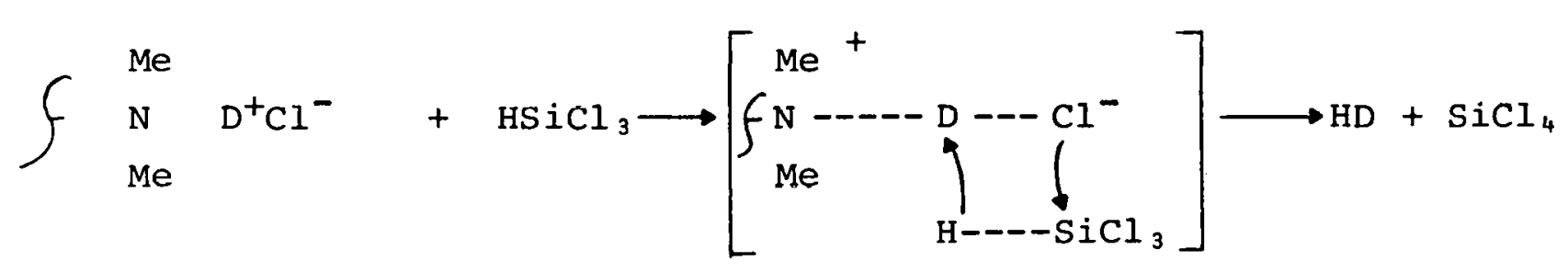


FIGURE $10_{10} H S_{i} \varphi_{3}+D C l \stackrel{A-2 l}{\longrightarrow}$

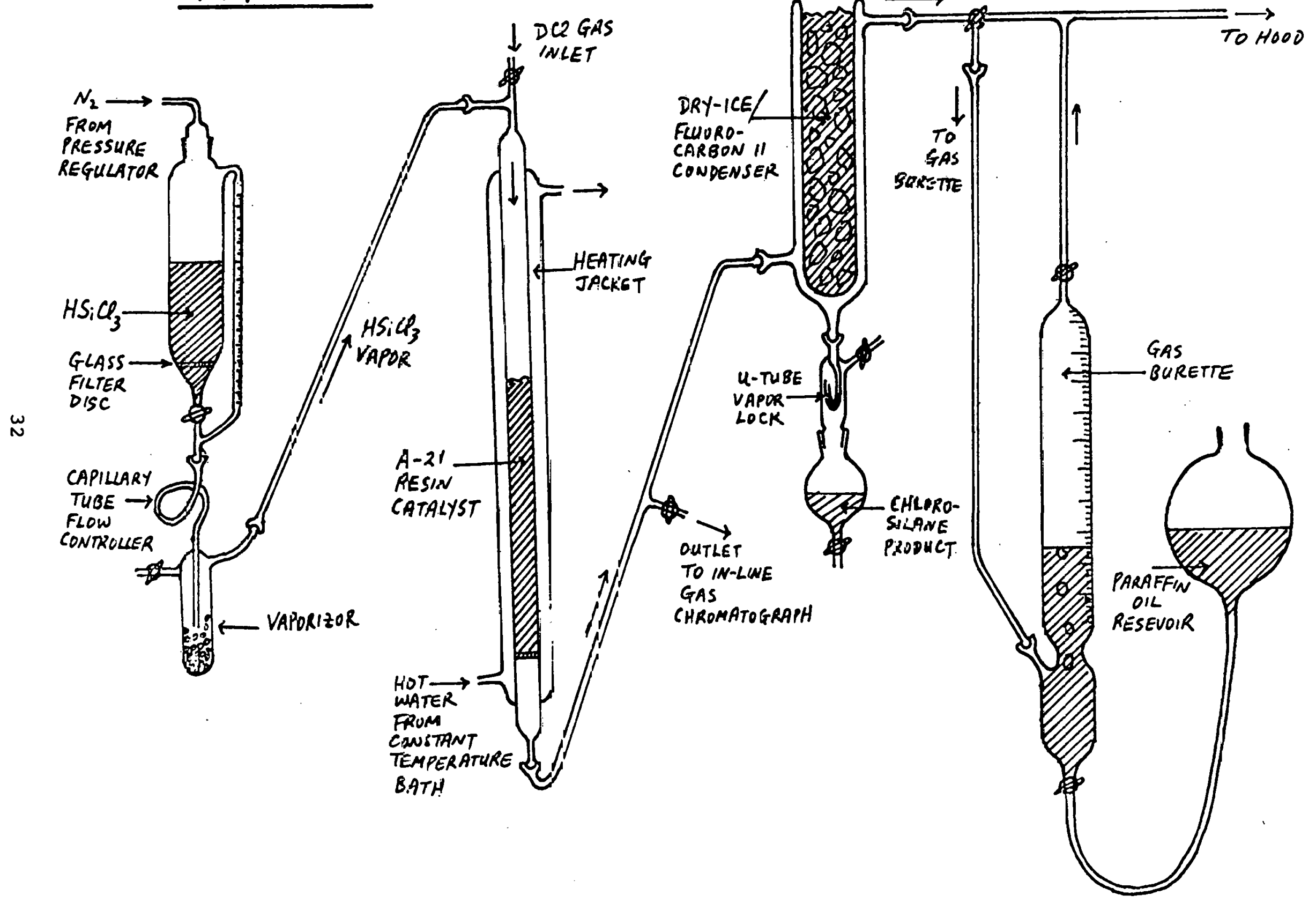




\section{TABLE VII}

DISPROPORTIONATION OF HSIC1 $1_{3}$ AND DC1 GAS IN THE PRESENCE OF A-21 RESIN CATALYST AT $60^{\circ}$

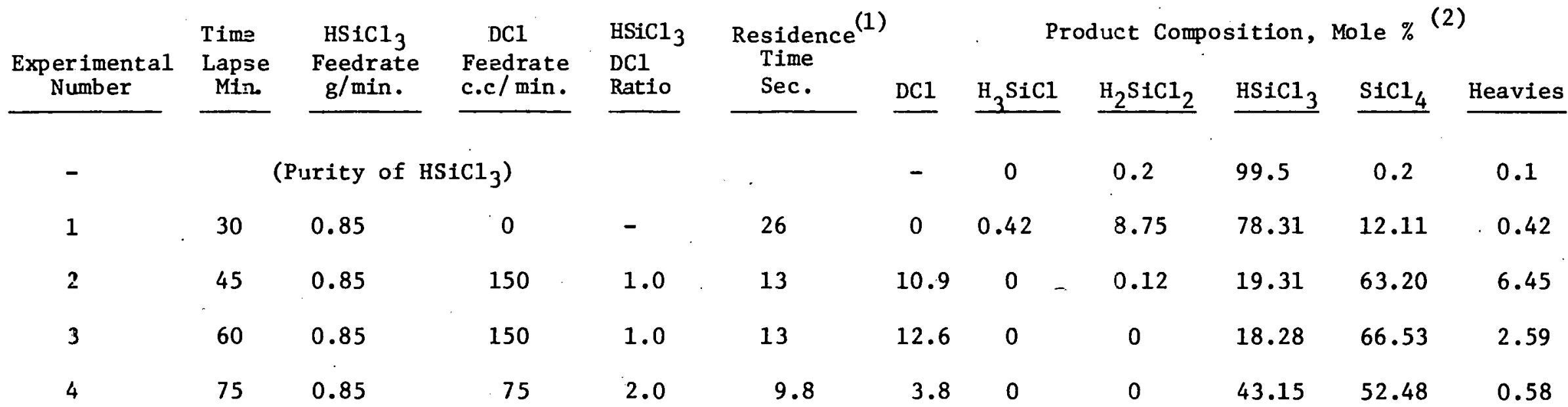

$\omega$

(Stop feeding DC1 at 75 Min.)

$\begin{array}{rrrrrrrrrrrrr}5 & 80 & 0.85 & 0 & - & 26 & 0 & 0 & 0.04 & 60.79 & 39.11 & 0.06 \\ 6 & 135 & 0.85 & 0 & - & 26 & 0 & 0.32 & 8.21 & .80 .42 & 10.76 & 0.29 \\ 7 & 165 & 0.85 & 0 & - & 26 & 0 & 0.40 & 9.02 & 79.46 & 10.86 & 0.26\end{array}$

(1) Based on void space in A-21 resin, 1.e., $65 \%$ of bed volume.

(2) By gas chromatography: deuteriated compounds were not separated from their hydrogen analogy, i.e., $\mathrm{HSiCl}_{3}$ represented $\mathrm{HSiCl}_{3}+\mathrm{DSiCl}_{3}$. 
Interestingly, substantial amount of isotopic exchange also took place as indicated by the presence of $\mathrm{H}_{2}, \mathrm{D}_{2}$, and some $\mathrm{DSiCl}_{3}$. The liquid chlorosilane product collected at the Dry-Ice condenser in Experiment No. 3 and No. 4 Table 7 were collected and analyzed by gas-liquid partition chromatography, glpc, and IR spectroscopy. Glpc analysis gave $0.17 \% \mathrm{H}_{2} \mathrm{SiCl}_{2}, 18.96 \% \mathrm{HSiCl}_{3}$ and $74.21 \% \mathrm{SiCl}_{4} \cdot$ The glpc analysis would not distinguish $\mathrm{HSiCl}_{3}$ from $\mathrm{DSiCl}_{3}$. A sample, $1.15 \mathrm{~g}$, of this chlorosilane mixture was vaporized and charged to the IR cell at a partial pressure of $58.2 \mathrm{~mm} \mathrm{Hg}$. The sample was scanned with the Beckman IR 4240 spectrometer. Absorption bands due to the presence of $S i H$ and SiD were observed and recorded. From the percent absorbance of the $\mathrm{SiH}$ and $\mathrm{SiD}$ absorption peaks, the concentration of $\mathrm{HSiCl}_{3}$ and $\mathrm{DSiCl}_{3}$ were determined from the calibration curves given in Figure 8 and Figure 9 to be $9.9 \mathrm{~mm} \mathrm{Hg}$ $\mathrm{HSiCl}_{3}$ and $6 \mathrm{~mm} \mathrm{Hg} \mathrm{DSiCl}{ }_{3}$ (or 17.0 mole $\% \mathrm{HSiCl}_{3}$ and $1.0 \mathrm{~mole} \%$ USilil ${ }_{3}$ ) respectively. The IR data, $188 \mathrm{HSiCl}_{3}+\mathrm{DSiCl}_{3}$, was in good agreement with the glpc data of $18.9 \% \mathrm{HSiCl}_{3}+\mathrm{DSiCl}_{3}$. The isotopic content in the trichlorosilane was calculated to be 5.6\% $\mathrm{DSICl}_{3}$. 'l'his small but significant amount of isotope exchange might be explained by a plausible reaction mechanism given in Equation (5).

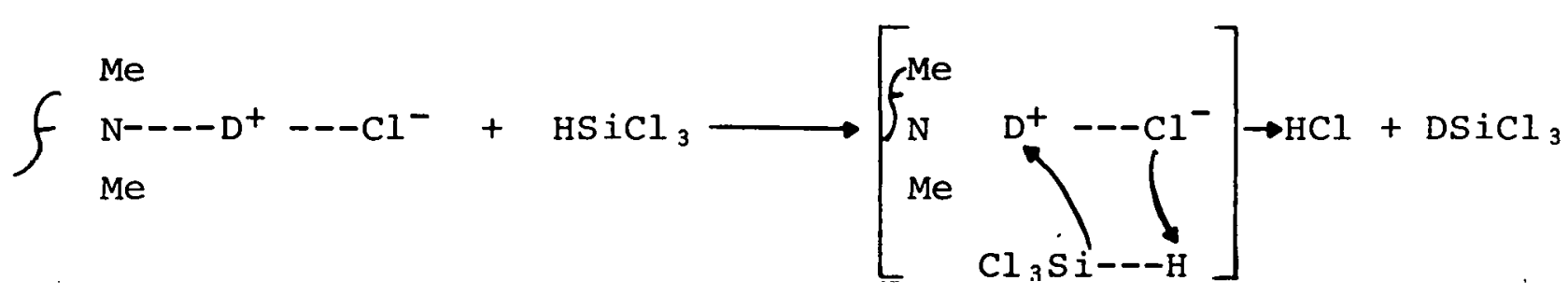

The extensive cleavage of $\mathrm{SiH}$ by $\mathrm{DCl}$ in the presence of $\mathrm{A}-21$ resin catalyst did not allow a clean measurement on this hydrogen-deuterium exchange mechanism. Undoubtly, some $\mathrm{DSiCl}_{3}$ and $\mathrm{HDSiCl}_{2}$ or $\mathrm{D}_{2} \mathrm{SiCl}_{2}$ formed in the redistribution reaction would also be readily cleaved by $\mathrm{DCl}$ to $\mathrm{SiCl}_{4}$ as indicated by the presence of substantial amounts of $\mathrm{D}_{2}$ and $\mathrm{H}_{2}$. The practically zero yield of dichlorosilane in Experiment No. 3 and No. 4 in Table 7 was interesting. Two plausible mechanisms which might account for the absence of dichlorosilane in the product are:

(a) The rate of $\mathrm{SiH}$ cleavage by $\mathrm{DCl}$ on the surface of A-21 resin was much faster than the rate of formation of $\mathrm{H}_{2} \mathrm{SiCl}{ }_{2}$ via disproupurtiunation of $\mathrm{HSiCl}_{3}$. In this respect, little $\mathrm{H}_{2} \mathrm{SiCl}_{2}$ would be formed in the first place.

(b) The rate of $\mathrm{SiH}$ cleavage was much faster in the case of $\mathrm{H}_{2} \mathrm{SiCl}_{2}$ than that of $\mathrm{HSICl}_{3}$, c.f., Equation (6) and (7). 


$$
\begin{aligned}
& \mathrm{H}_{2} \mathrm{SiCl}_{2}+\mathrm{DCl} \frac{\mathrm{A}-21}{\text { fast }} \mathrm{HD}+\mathrm{HSiCl}_{3} \\
& \mathrm{HSiCl}_{3}+\mathrm{DCl} \stackrel{\mathrm{A}-21}{\mathrm{HD}}+\mathrm{SiCl}_{4}
\end{aligned}
$$

In this respect, $\mathrm{H}_{2} \mathrm{SiCl}_{2}$ was formed in the disproportionation reaction but was rapidly destroyed. After 75 minutes of reaction, the DCl gas feed was shut off. Experiment No. 5 in Table 7 showed that after 5 minutes since $\mathrm{DCl}$ gas was stopped, extensive cleavage of $\mathrm{SiH}$ to give high yield of $\mathrm{SiCl}_{4}$ still occurred. This was most likely due to the residual amount of DCl remained in The A-21 resin as amine hydrochloride. Data in Table 7 Experiment No. 6 and No.7 showed that after one hour and one and a half hours of reaction since $\mathrm{DCl}$ gas was shut off, the disproportionation of $\mathrm{HSiCl}_{3}$ in the presence of $\mathrm{A}-21$ resin catalyst returned to normal to yield about $10 \% \mathrm{H}_{2} \mathrm{SiCl}_{2}$ and $\mathrm{SiCl}_{4}$.

In conclusion, the above experimental data indicated that the amine hydrochloride could not be the active catalyst for the disproportionation of chlorohydrosilanes, since any $\mathrm{HCl}$ present (DCl in this case) would be readily destroyed to form hydrogen gas in an irreversible $\mathrm{SiH}$ cleavage reaction. In view of this rapid $\mathrm{SiH}$ cleavage reaction to form useless hydrogen gas at the expense of valuable SiH compounds, it casted much doubt on the merit of "activating" the A-2l resin catalyst with $\mathrm{HCl}$. The previously observed reaction rate increase after $\mathrm{HCl}$ treatment of the A-2l resin catalyst was most likely due to some other extraneous factors not understood at the present time. More work is in progress.

\section{CONCLUSIONS}

The production of silane via redistribution of dichlorosilane using a tertiary amine ion exchange resin catalyst is a viable process which follows close to theoretical relationships. The deviations of the silane-monochlorosilane system from ideal vaporliquid equilibrium result in enhanced silane purity at pressures above about $20 \mathrm{psig}$ and will simplify final purification. The ability of the ion exchange resin catalyst to redistribute virtually any mixture of hydrochlorosilanes can be used to advantage in reducing overall system size and complexity. 


\section{NEW TECHNOLOGY}

period.

No reportable items of new technology occurred during this

\section{PLANNED ACTIVITIES FOR NEXT QUARTER}

1. Continue mini-plant operations to produce silane for electronic evaluation.

2. Install a hydrogenation reactor system.

3. Continue laboratory studies on the hydrogenation of $\mathrm{SiCl}_{4}$ with respect to catalyst, temperature, and pressure effects. 
Figure 11

Total Cost/Labor Hour

Plan for Low Cost Silane Project

Revised
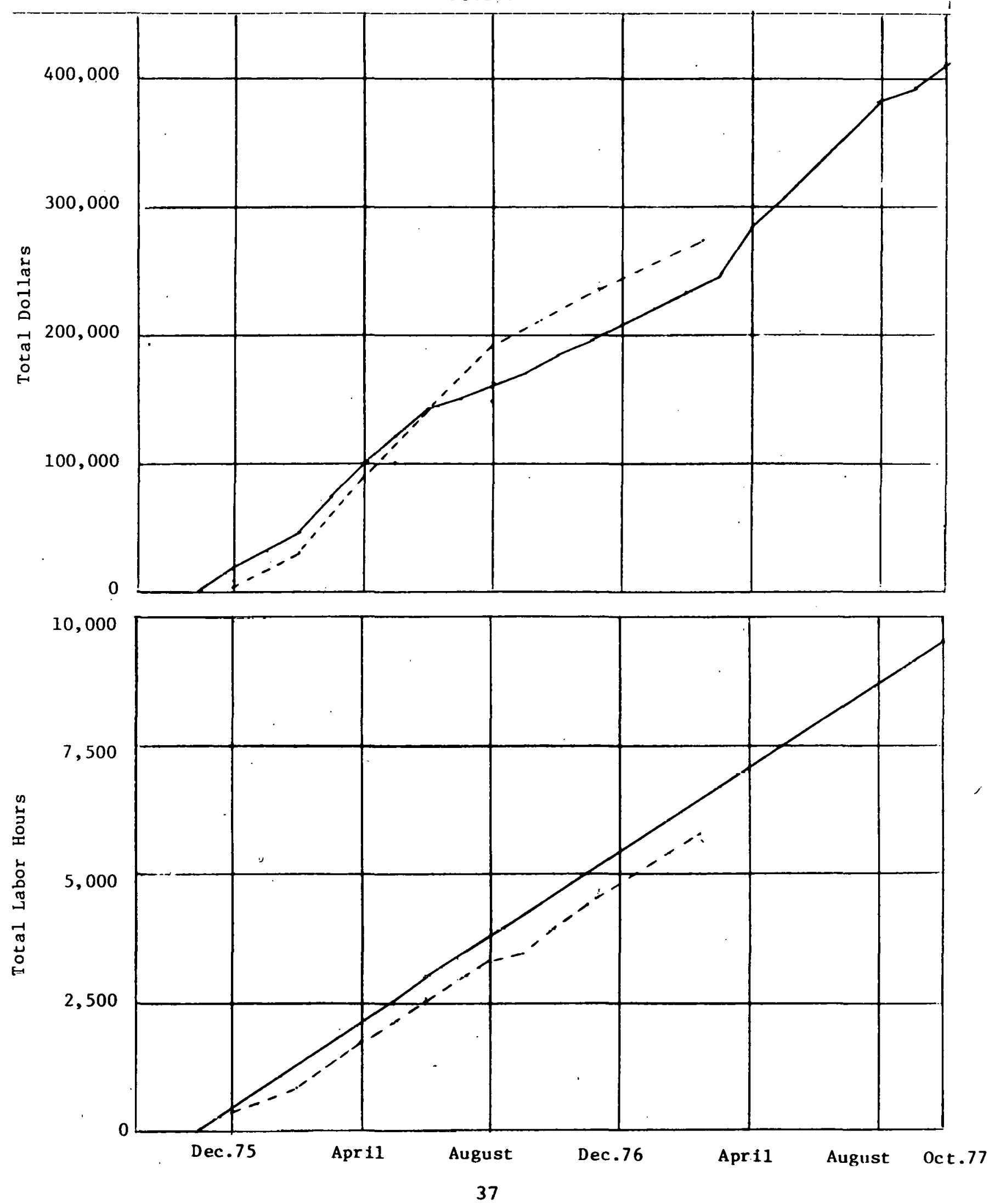
FIGURE 12

REVISED IMPLEMENTATION PLAN

\section{TASK}

Initial Start Up Silane Plant Data Collection and Analysis Design Hydrogenation Unit

Purchase Reactor

Final Design

Installation

Start Up

Data Collection and Analysis

Design Maxi-Plant

Purchase Equipment

Final Design

Installation

Start Up

Data Collection and Analysis

Integration of Sub-units

\section{PROCESS STUDIES}

$\omega_{\infty}$ Determine Reaction Parameter Energy and Mass Balarice

Kinetic Studies

Process Evaluation

Process Cost Estimation

FINAL REPOR!
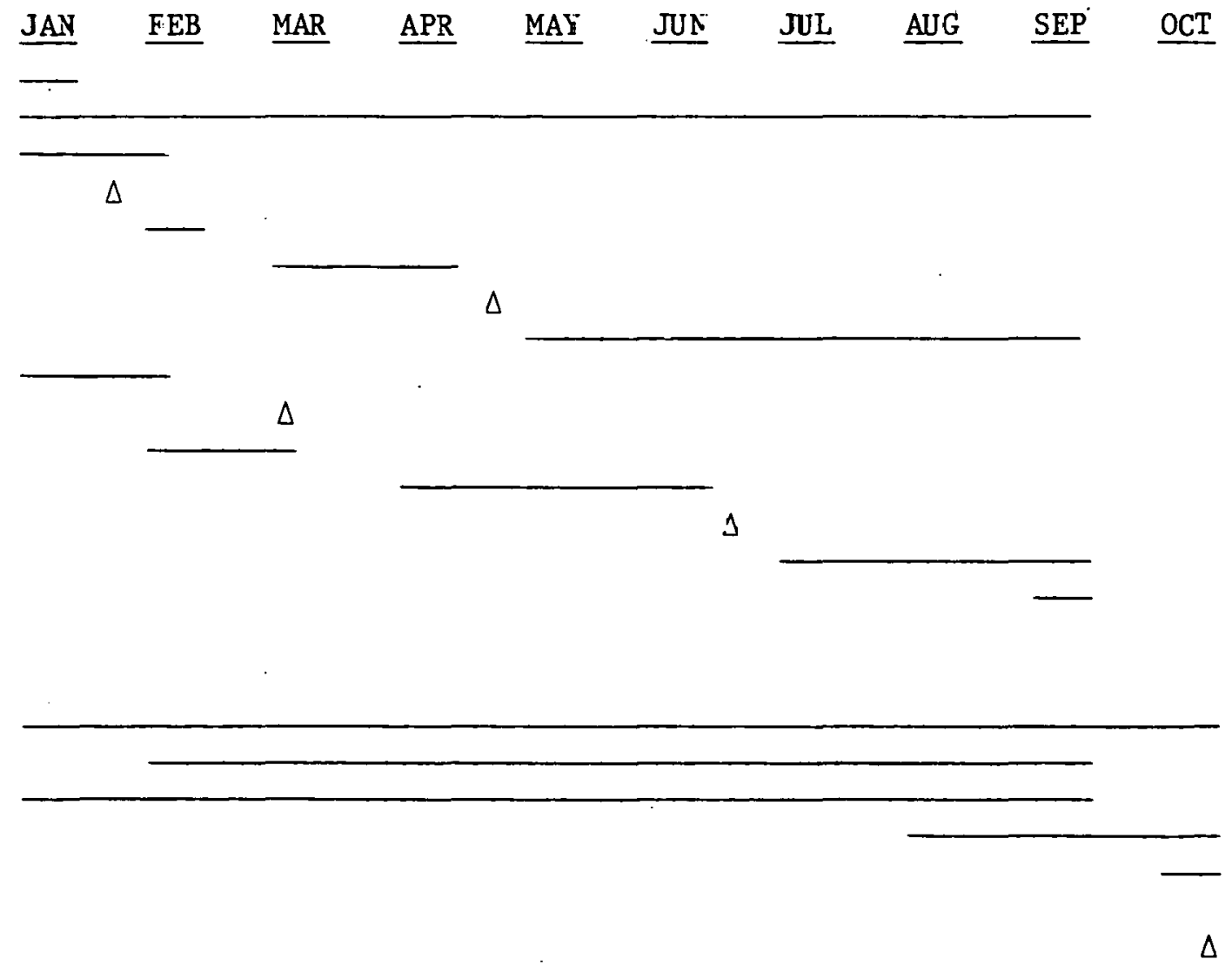
SECTION B

The Production of Silicon from silane, $\mathrm{SiH}_{4}$

Parma Technical Center

$\begin{array}{lll}\text { Program Manager: } & \text { E. G. Farrier } & \text { Date: April 1, } 1977 \\ \text { Principal Scientist: } & \text { J. Rexer } \\ \text { Development Engineer: } & \text { M. R. Malay }\end{array}$

$\underline{\text { ABSTRACT }}$

The objective of the Parma Technical Center Program is to establish the economic feasibility of manufacturing solar and/or semiconductor grade polycrystalline silicon through the pyrolysis of silane $\left(\mathrm{SiH}_{4}\right)$. Union Carbide Corporation pioneered two low cost, high volume methods (fluid bed process and a free space process) of pyrolyzing silane. The technical and engineering feasibility of both methods was experimentally established. Experiments with a Fluid Bed Reactor established that fully dense coherent coatings of silicon can be obtained on silicon seed particles. However, the restricted operating conditions needed to obtain the coherent coatings imposed a severe economic limitation on this process. The process with the greatest potential for a low cost, high volume operation is the free space pyrolysis process. Preliminary experiments established that undiluted silane can be thermally decomposed into a powder product at yields greater than $80 \%$. The free space reactor experiments also led to a proposed model of the decomposition and heat transfer mechanism. On the basis of this model, a High Purity Reactor (HPR) was designed and constructed. This reactor can currently be operated for runs sufficient to produce approximately $1.5 \mathrm{~kg}$ of powder per run. It was designed for a production rate of $0.3 \mathrm{~kg} / \mathrm{hr}$. and has been operated for short periods of time at $5 \mathrm{~kg}$ of silicon per hour. Continuous operation has not been demonstrated. The powder produced is composed of submicron size particles. Consolidation of the powder through melting and compaction techniques is under investigation. Loose powder or pellet sintering may provide a feed stock for the Fluid Bed Reactor. The powder produced during the next quarter should be of sufficient purity to justify chemical evaluation. 


\title{
SECTION B
}

Table of Contents

\begin{abstract}
INTRODUCTION $\ldots \ldots \ldots \ldots \ldots \ldots \ldots \ldots \ldots \ldots \ldots \ldots \ldots \ldots \ldots \ldots \ldots$

DISCUSSION ............................44

I. Silane Pyrolysis.......................44

II. Powder Consolidation.......................49

CONCLUSIONS...............................49

PROJECTED SECOND QUARTER ACTIVITIES.................. 50

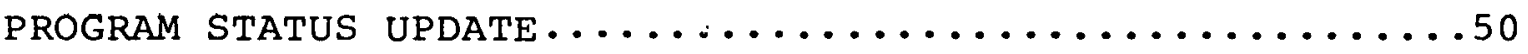




\section{SECTION B}

\section{List of Figures}

\begin{tabular}{|c|c|}
\hline $1 B$ & High Purity Free Space Reactor Assembly .......42-a \\
\hline $2 B$ & 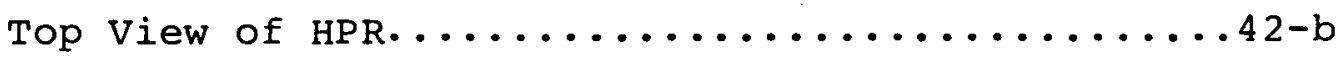 \\
\hline $3 \mathrm{~B}$ & 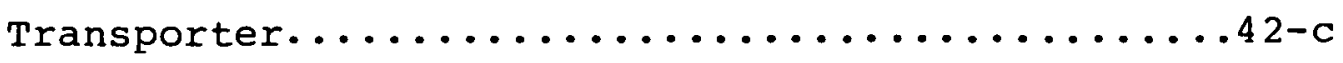 \\
\hline $4 \mathrm{~B}$ & Transporter Positioned to Lift the HPR .......42-d \\
\hline $5 B$ & HPR controls........................42-e \\
\hline $6 \mathrm{~B}$ & High Purity Reactor Assembly sketch..........43 \\
\hline $7 \mathrm{~B}$ & Sample Collector Assembly Sketch.............48 \\
\hline $8 \mathrm{~B}$ & SEM Photomicrographs of HPR Powders............49-a \\
\hline $9 B$ & Implementation Plan............ \\
\hline $10 \mathrm{~B}$ & Direct Labor Hours........................ 52 \\
\hline $11 \mathrm{~B}$ & Total cost Plan....... \\
\hline
\end{tabular}

\section{List of Tables}

$\underline{\text { Table }}$ 


\section{INTRODUCTION}

Under Union Carbide Corporation sponsorship, a program was initiated whose objective was to devise an economic means of manufacturing semiconductor grade polycrystalline silicon through the pyrolysis of silane. At the Parma Technical Center, silane pyrolysis in a Fluid Bed Reactor and in a free space reactor were examined. The original concept envisioned using either the reactors separately to produce the lowest cost acceptable polycrystalline product, or with the free space reactor supplying the seed for the fluid bed. It was thought that the deposition of coherent and fully dense silicon coatings onto the seed particles would improve the handling characteristics of the particles while decreasing their surface area. Experimental data indicated that the concept of using the fluid bed to increase the size of the particles generated in the free space reactor is not the most practical method of consolidation. Since the particles generated in the free space reactor are not sufficiently larger consolidation of this fine powder to produce a coarser material is part of the current program.

Experiments with $76 \mathrm{~mm}$ and $102 \mathrm{~mm}$ free space reactors showed that reactor design and operating conditions can be obtained that minimize the extent of silicon or silane reaction with the reactor wall. On the basis of these experiments, a model of the decomposition and heat transfer mechanism was proposed. The proposed model served as a guide in achieving pyrolysis efficiencies exceeding $80 \%$. The model also served as a guide in designing a larger (194 mm diameter x $914 \mathrm{~mm}$ long) reactor which is currently in use.

The current free space reactor is now called a $\mathrm{High}$ Purity Reactor (HPR) since the purity of the product from this reactor will be evaluated. Figures $1 \mathrm{~B}$ through $5 \mathrm{~B}$ are photographs of the HPR and many of its components. Figure 6B is a sketch of the HPR reactor assembly (not to scale) as originally constructed. The reactor itself is a $194 \mathrm{~mm}$ I.D. X $914 \mathrm{~mm}$ long Schedule 80 Monel pipe. The $610 \mathrm{~mm}$ long hot zone is heated inductively. The stainless steel reartor lid contains two $51 \mathrm{~mm}$ diameter sight glasses, four conax fittings for thermocouples or other probes, and one centrally located conax seal for the gas injector tube. vacuum tight seals are obtained with "Grafoil" (a Union Carbide Corporation graphite sheet product) gaskets. The reactor is bolted onto a stainless steel settling chamber cover plate which contains a compound pressure/vacuum gauge and a relief valve. The settling chamber is a stainless steel vessel whose inside dimensions are approximately $475 \mathrm{~mm}$ diameter x $603 \mathrm{~mm}$ deep. 


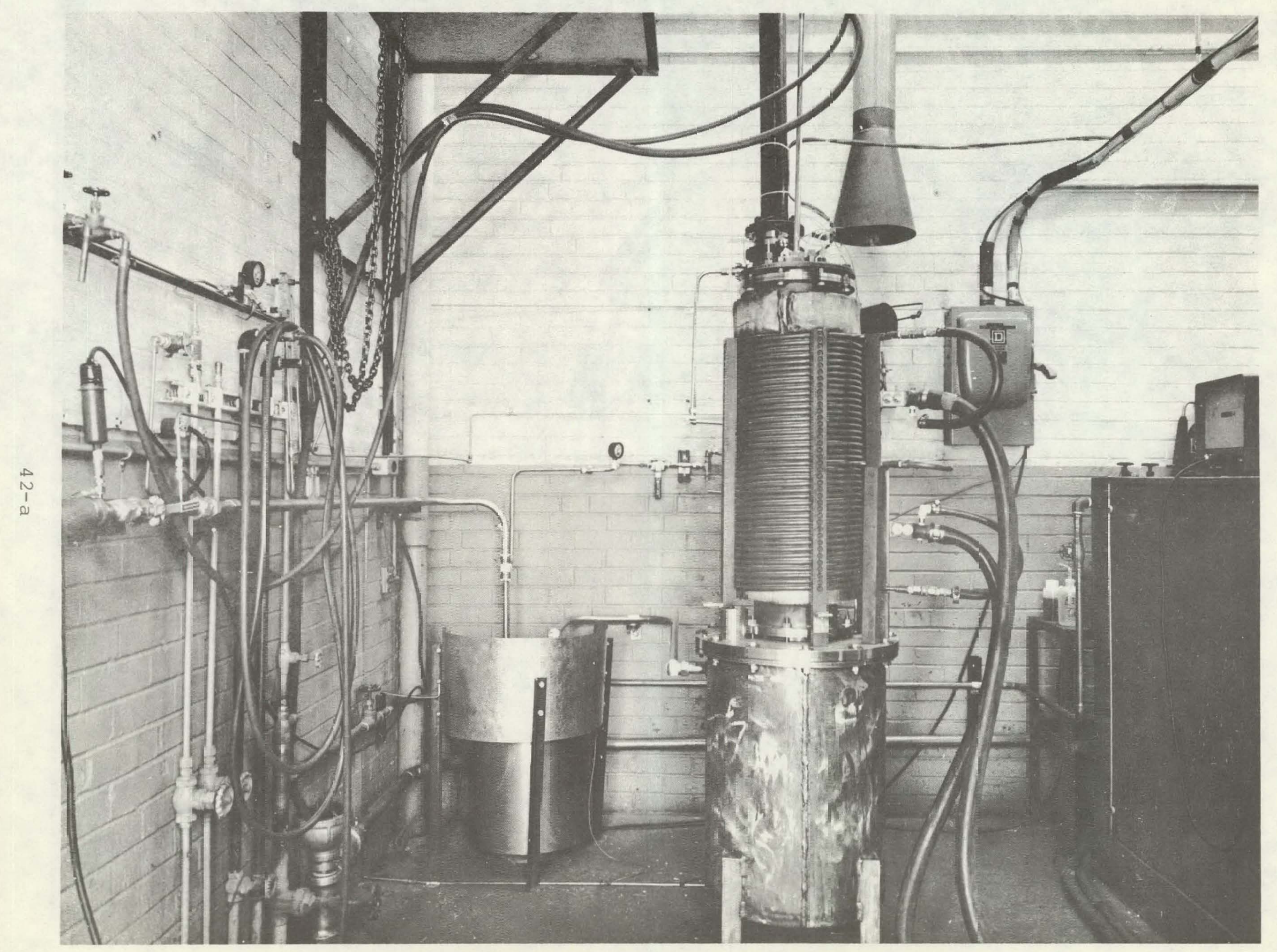


Figure 2B

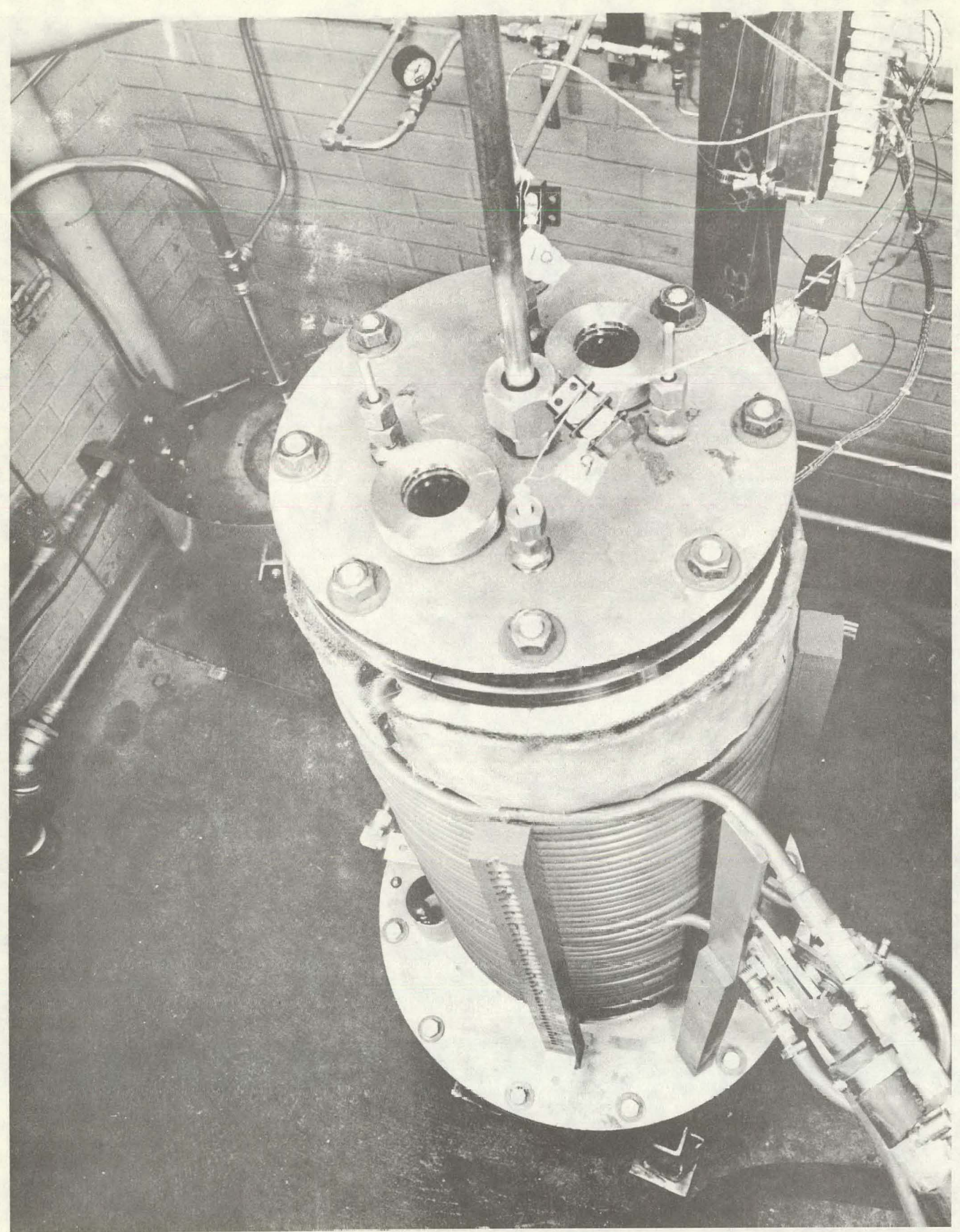


Figure $3 \mathrm{~B}$

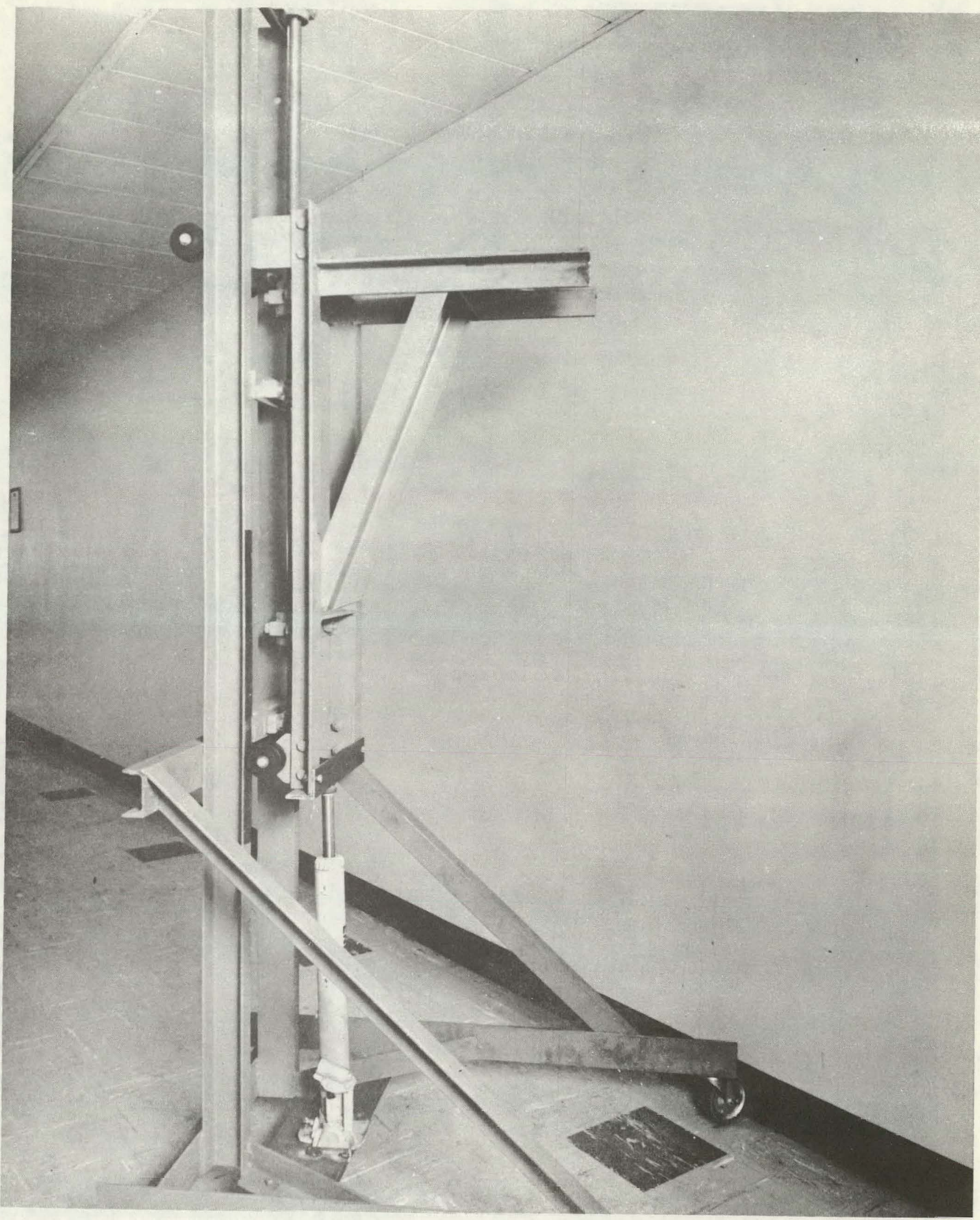

$42-c$ 
Figure 4B

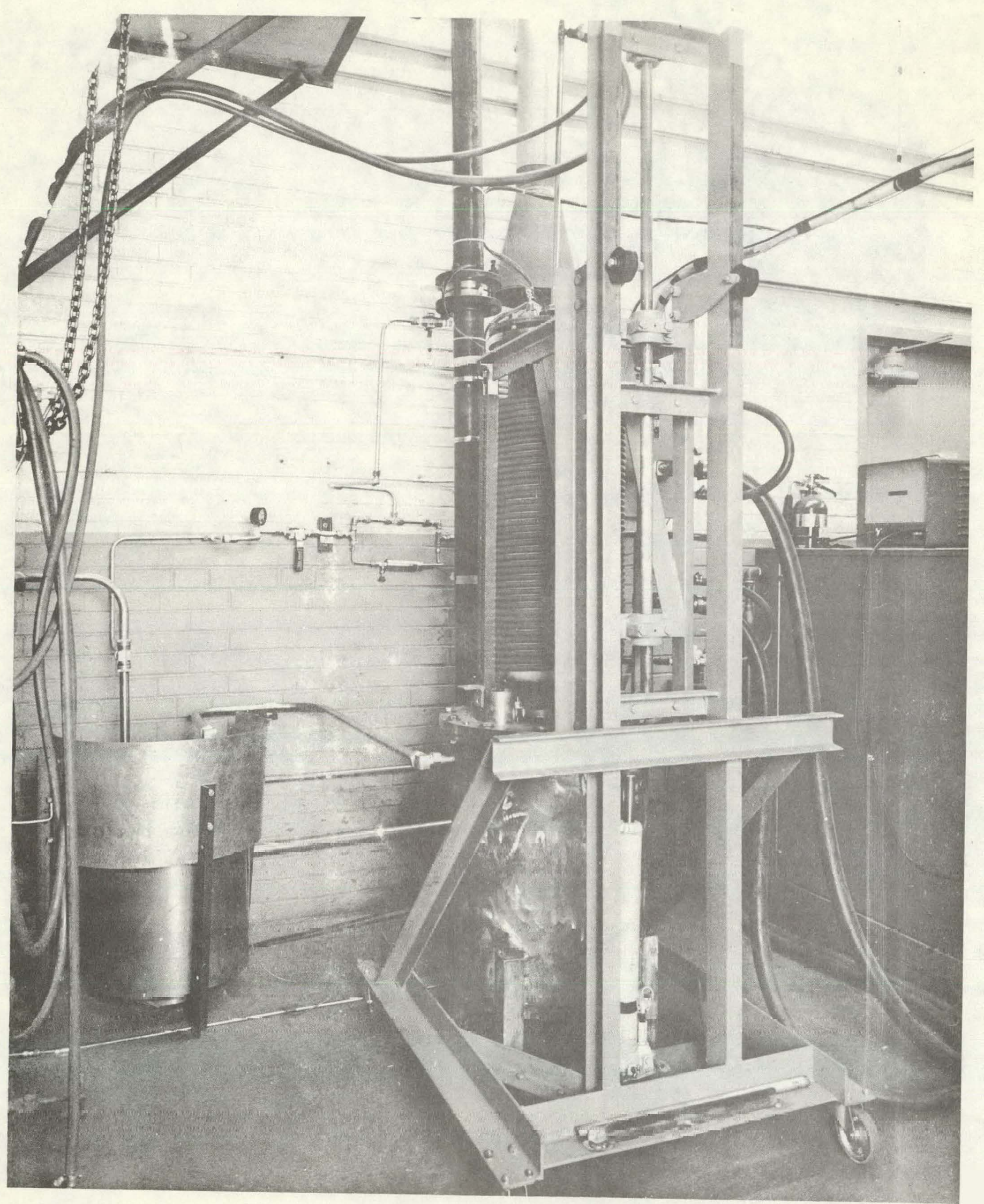




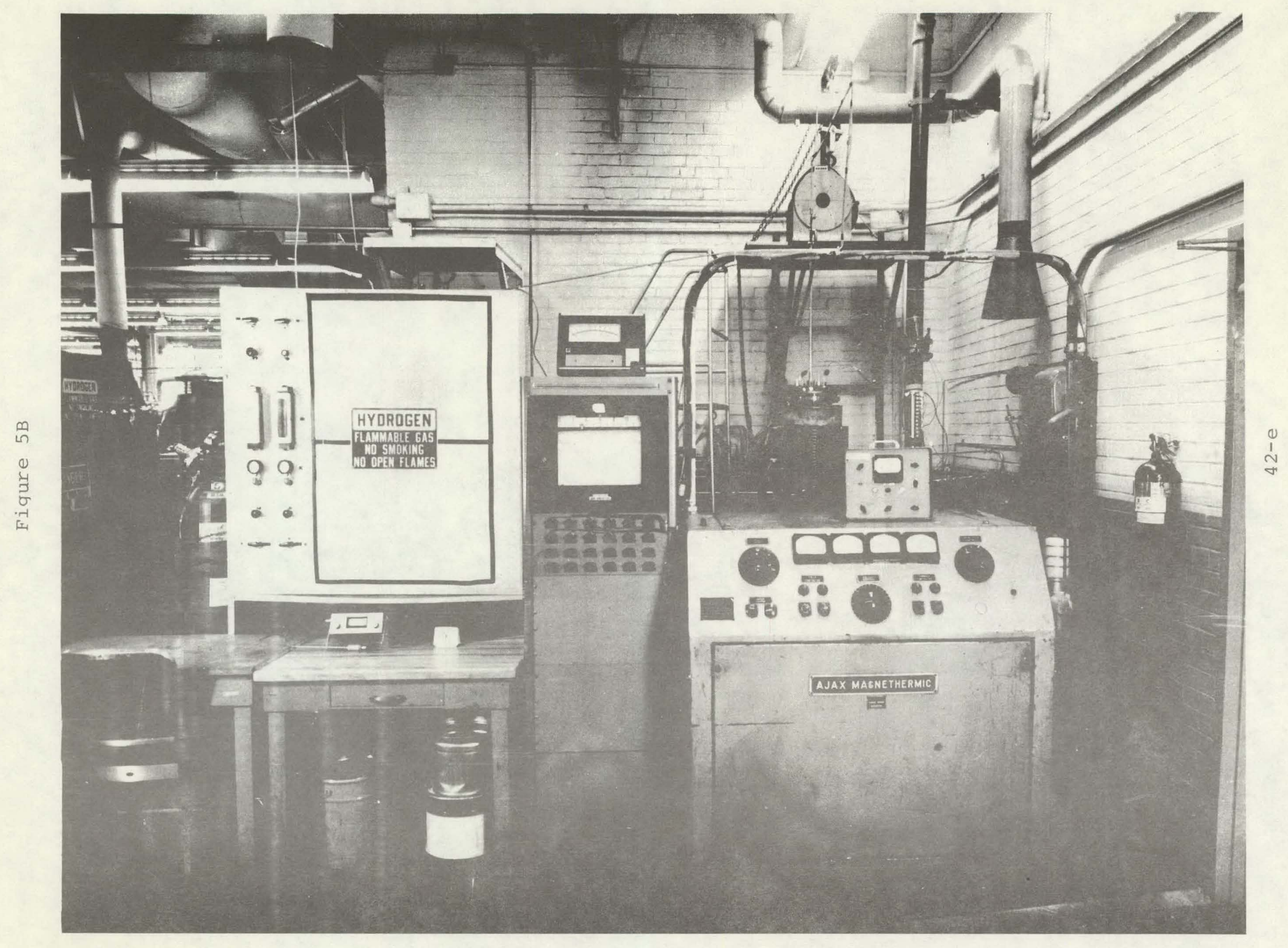




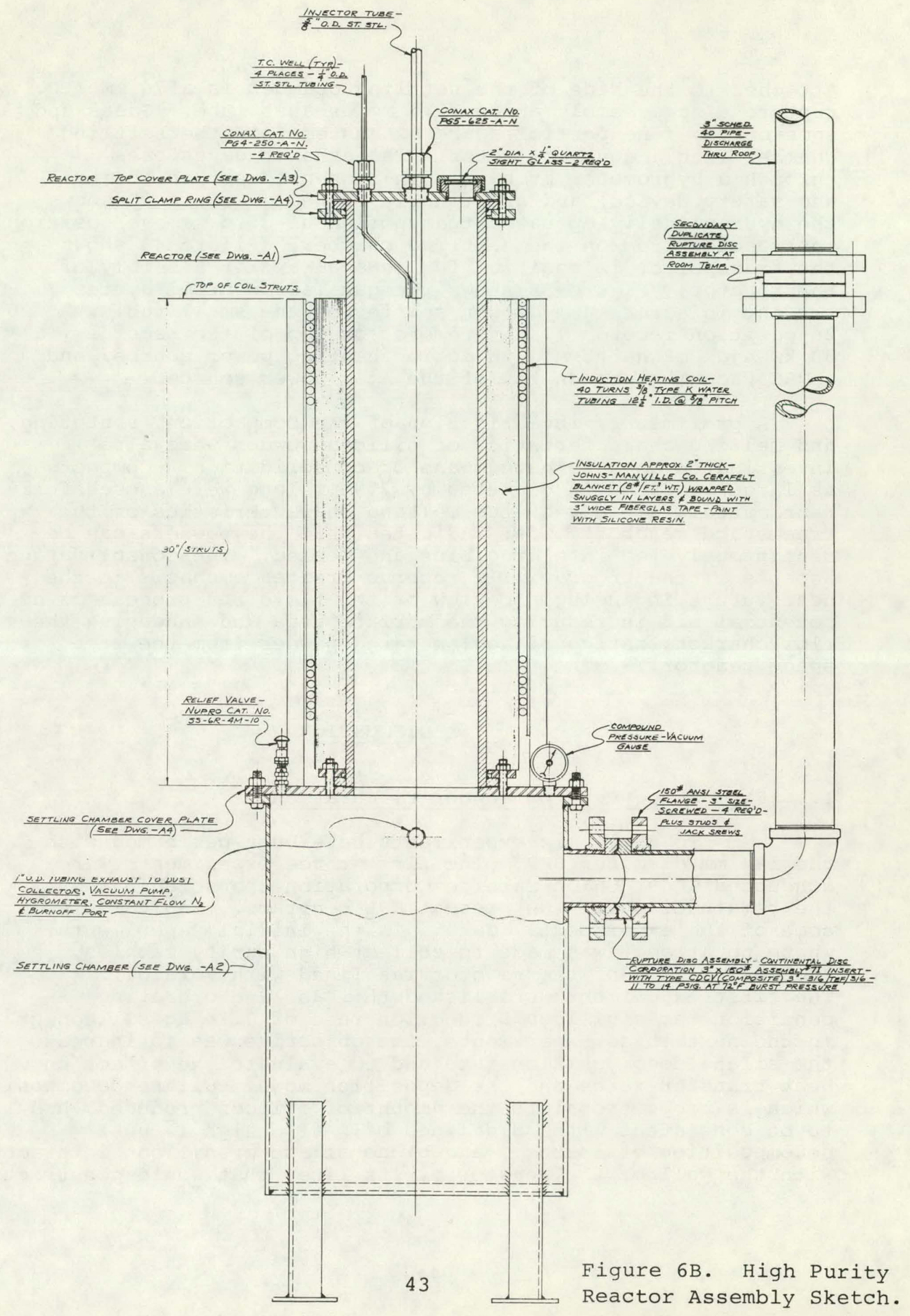


Attached to the side of the settling chamber is a $76 \mathrm{~mm}$ I.D. rupture disc assembly and a $25.4 \mathrm{~mm}$ exhaust tube. Gases and some of the fine particles are exhausted from the settling chamber into a dust collector. The exhaust gases pass through a hygrometer probe (an in-line process monitoring and safety device) and are finally burned. Figure 3B shows the hydraulically operated transporter used to remove/position the reactor from/on the settling chamber. Figure 4B shows the transporter in position for removal and/or assembly of the reactor. Figure $5 \mathrm{~B}$ shows the gas flow control system for the injector, a hydrogen sniffer on the small table, a 24-position recorder, a hygrometer on top of the recorder, a $30 \mathrm{kw}$ Ajax magnathermic injection heating power source, and a NRC vacuum gauge on top of the Ajax power source.

A preliminary invesliyaliun of the compaction, sintering, and melting characteristics of silicon powder were also investigated as alternate means of consolidation. Compacts as large as $83 \mathrm{~mm}$ in diameter by $229 \mathrm{~mm}$ long were successfully fabricated. A study of the melting characteristics of the free space reactor powder indicated that the powders can be continuously fed into crucibles and melted. The consolidation aspects of the program will receive greater emphasis in the near future including a review of the fluid bed process as a potential aid in reducing the surface area and enhancing the flow characteristics of agglomerated powder from the free space reactor.

\section{DISCUSSTON}

\section{F'ree Space Reactor Powder Preparation}

To date, six experiments have been performed with the $194 \mathrm{~mm}$ diameter HPR. The first three experiments were conducted under Union Carbide Corporation sponsorship and the remainder under the present JPL contract. Table I lists some of the experimental data. In the initial experiments, where no attempt was made to collect high purity samples, the inside wall of the reactor was lined with "Grafoil." The first experiment established the baseline operating conditions at a silicon production rale of $0.30 \mathrm{~kg}$ silicon/hr. In the next three experiments, the objective was to increase the silane decomposition rate and to evaluate the effect on heat transfer rates and the deposition mode. Silane decomposition, which is proportional to the amount of silicon produced, had to be consistent with guidelines of: a) a high ( $580 \%$ ) decomposition efficiency, and b) no silane or silicon interactions with the wall of the reactor or its liner that would constrict 
Table IB

HPR EXPERIMENTAL DAIA

\begin{tabular}{|c|c|c|c|c|c|c|c|c|c|c|}
\hline \multirow[b]{2}{*}{$\begin{array}{c}\text { Experiment } \\
\text { Number }\end{array}$} & \multicolumn{6}{|c|}{ CONDITIONS } & \multicolumn{4}{|c|}{ RESULTS } \\
\hline & \begin{tabular}{|c|} 
Max. \\
$\mathrm{SiH}_{4}$ Flow \\
$(\mathrm{f} / \mathrm{min})$. \\
\end{tabular} & $\begin{array}{c}\mathrm{D}_{\mathrm{C}} \\
(\mathrm{mm})\end{array}$ & $\begin{array}{r}\mathrm{V}_{\circ} \mathrm{Max} \\
(\mathrm{m} / \mathrm{sec} .)\end{array}$ & \begin{tabular}{|c|} 
Max. Prod. \\
Rate \\
$(\mathrm{kgSi} / \mathrm{hr})$. \\
\end{tabular} & \begin{tabular}{|l|} 
Reactor \\
Centcr Wall \\
Temp. $\left({ }^{\circ} \mathrm{C}\right)$ \\
\end{tabular} & $k w$ & $\begin{array}{l}\mathrm{Kg} \mathrm{Si} \\
\text { Prod. }\end{array}$ & \begin{tabular}{|l} 
Decomp. \\
Eff. \\
$(\%)$
\end{tabular} & \begin{tabular}{|l|} 
Avg. Part. \\
Diam. \\
$(\mu \mathrm{m})$
\end{tabular} & Remarks \\
\hline HPR $-271-12-1$ & 4 & 2.0 & 21 & 0.3 & $100 c-1045$ & $7-8$ & 0.28 & 92 & & $\begin{array}{l}\text { Baseline. Product all powder } \\
\text { (light brown). }\end{array}$ \\
\hline$H P R-271-12-2$ & 17.4 & 2.0 & 90 & 1.3 & $990-1075$ & $6 \frac{1}{2}-7 \frac{1}{2}$ & 0.85 & 86 & 0.23 & $\begin{array}{l}\text { Powder was dark brown. Seven } \\
\text { percent of product was semi- } \\
\text { solid injector cones. }\end{array}$ \\
\hline HPR $-271-12-3$ & 60.7 & 4.6 & 62 & 4.6 & $995-1030$ & $9-11$ & 1.46 & 98 & 0.30 & $\begin{array}{l}\text { Dark brown powder. Seven percent } \\
\text { of product was semi-solid } \\
\text { injector cones. }\end{array}$ \\
\hline$H P R-626-1-1$ & 67 & 4.6 & 68 & 5.1 & $1001)-1010$ & $9-12$ & 0.81 & 85 & 0.35 & $\begin{array}{l}\text { Dark brown to dark grey powder. } \\
\text { Three small semi-solid lumps } \\
(0.3 \% \text { of product }) \text {. }\end{array}$ \\
\hline HPR $-626-1-2$ & 44 & 2.0 & 233 & 3.4 & $1003-1025$ & $8-10$ & 1.58 & $99+$ & & $\begin{array}{l}\text { Dark brown powder. One large and } \\
\text { several small semi-solid lumps } \\
\text { ( } 4 \% \text { of product }) \text {. }\end{array}$ \\
\hline $\begin{array}{l}\text { *The letters } \\
\text { Contract No. }\end{array}$ & HPR stand & $\begin{array}{l}\text { for } \\
\text { and th }\end{array}$ & $\begin{array}{l}\text { igh Purit } \\
\text { e last No }\end{array}$ & $\begin{array}{l}\text { Reactor, } \\
\text { designates }\end{array}$ & $\begin{array}{l}\text { fos. } 626-1 \text { re } \\
\text { the experim }\end{array}$ & $\begin{array}{l}\text { fer to } t \\
\text { ent numb }\end{array}$ & $\begin{array}{l}\text { e first } \\
\text { er. }\end{array}$ & otebook & to be used & under \\
\hline
\end{tabular}


the flow of gas. In all three experiments, the silane flow was increased until the maximum capabilities of the flow meters and regulating valves were reached. In the final experiment of this series, a production rate of $5 \mathrm{~kg}$ of silicon/hr., for approximately one minute, was obtained. In experiment No. HPR-626-1-2, the objective was to establish the relationship between the injected gas velocity and the reactor hot zone length with the present reactor configuration. The design gas velocity was $21 \mathrm{~m} / \mathrm{sec}$. For this experiment, a gas velocity of $233 \mathrm{~m} / \mathrm{sec}$. was achieved at a pyrolysis efficiency of over $99 \%$. This encouraging result indicates further latitude in potential of the free space reactor.

During an experimental run, the efficiency of the silane decomposition is qualitatively estimated visually by noting the color of burning exhaust gases. From past experience, it is known that the exhausted hydrogen burns with an orange flame (an absolutely pure hydrogen flame should be colorless); silane burns with a bright white flame. A definite white discoloration of the flame has, in the past, been indicative of a pyrolysis efficiency of less than $80 \%$.

In most pyrolysis experiments, hollow cones of weekly bonded silicon form at the tip of the injector. Since they are hollow, they become an extension of the injector. The cones are loosely attached to the injector and during prolonged experimental runs the cones fall off and new ones form. In Experiment HPR-626-1-1, the semisolid pieces of silicon amounted to only $0.3 \%$ of the product. This smaller quantity is a good indication that the cones can be entirely eliminated if desired.

It was noted after each experiment that a layer of the finely divided powder has coated everything in the reactor. The portion of the reactor directly adjacent to the induction coil was the only part where there may be an indication of some silane or silicon interaction with the "Grafoil" furnace liner. In this heat-affected zone, the liner beneath the loosely adhering powder was dull qrey instead of black, with some portions rainbow colored.

$x$-ray diffraction and fluorescence analysis of the dull grey discolored portion of the liner indicates that a very thin layer of silicon has coated the liner. No silicon carbide was detected. It is thought that a bonded coating of silicon develops at the start of a pyrolysis experiment. Once steady state conditions are established and heat transfer proceeds through the movement of silicon particles and the gas phase, undecomposed silane molecules no longer reach the reactor wall. The extent of any silane decomposition is slight. Attempts to establish a deposition rate from weight or thickness measurements were not successful. 
In a simulated experimental run, an attempt was made to determine if any of the "Grafoil" reactor liner discolorations could be attributed to thermal and/or chemical attack by adsorbed gases, minute leaks, or "Grafoil" bearing impurities. The run simulation was conducted exactly as a regular pyrolysis experiment with the exception that flowing argon was substituted for the silane. Slight greying of the "Grafoil" liner did occur indicating some affect. The back side of the liner, protected from the flowing gases, retained its black luster indicating no thermal affects. A typical analysis of the grade of "Grafoil" used in the HPR shows an ash content of approximately 3 percent with the major impurities being iron, aluminum, silicon, and calcium. Consequently, "Grafoil" is an excellent source for contamination of the silicon powder with elements other than just carbon. In addition, due to the short duration of the experiments performed in the HPR, degassing of the "Grafoil" may contribute gaseous atmospheric contaminants for prolonged periods. As the first major step towards extracting a silicon powder sample for purity analysis, the "Grafoil" liner was replaced with one of nickel.

To minimize contamination of the fine silicon powder through extensive handling, an effort is being made to have a powder sample sealed in a container before dismantling the reactor assembly. To accomplish this, a thermally activated sample extractor was designed and constructed (Figure 7B). The extractor fits inside of the settling chamber. The sample collecting container will be purged of air contaminants during the normal system evacuation cycle. During the heatup cycle of an experiment, the lid of the container will assume a vertical position. It will maintain this position throughout the silane pyrolysis portion of the experiment. On cooldown, the lid will automatically assume a horizontal position pressed against the container opening. After the reactor is removed from the settling chamber, the lid will be fastened to the sample container and subsequently the container will be removed from the settling chamber.

For the purposes of safety and economics, operation of the HPR should be done at the lowest possible temperature. It is technically feasible to achieve this by preheating the silane to $350^{\circ}-400^{\circ} \mathrm{C}$ before it is injected into the pyrolysis reactor. During this quarter, a furnace and heat exchanger was installed near the gas injector of the HPR. By preheating the silane, it may be possible to operate the reactor at temperatures significantly below the present $1000^{\circ} \mathrm{C}$. 

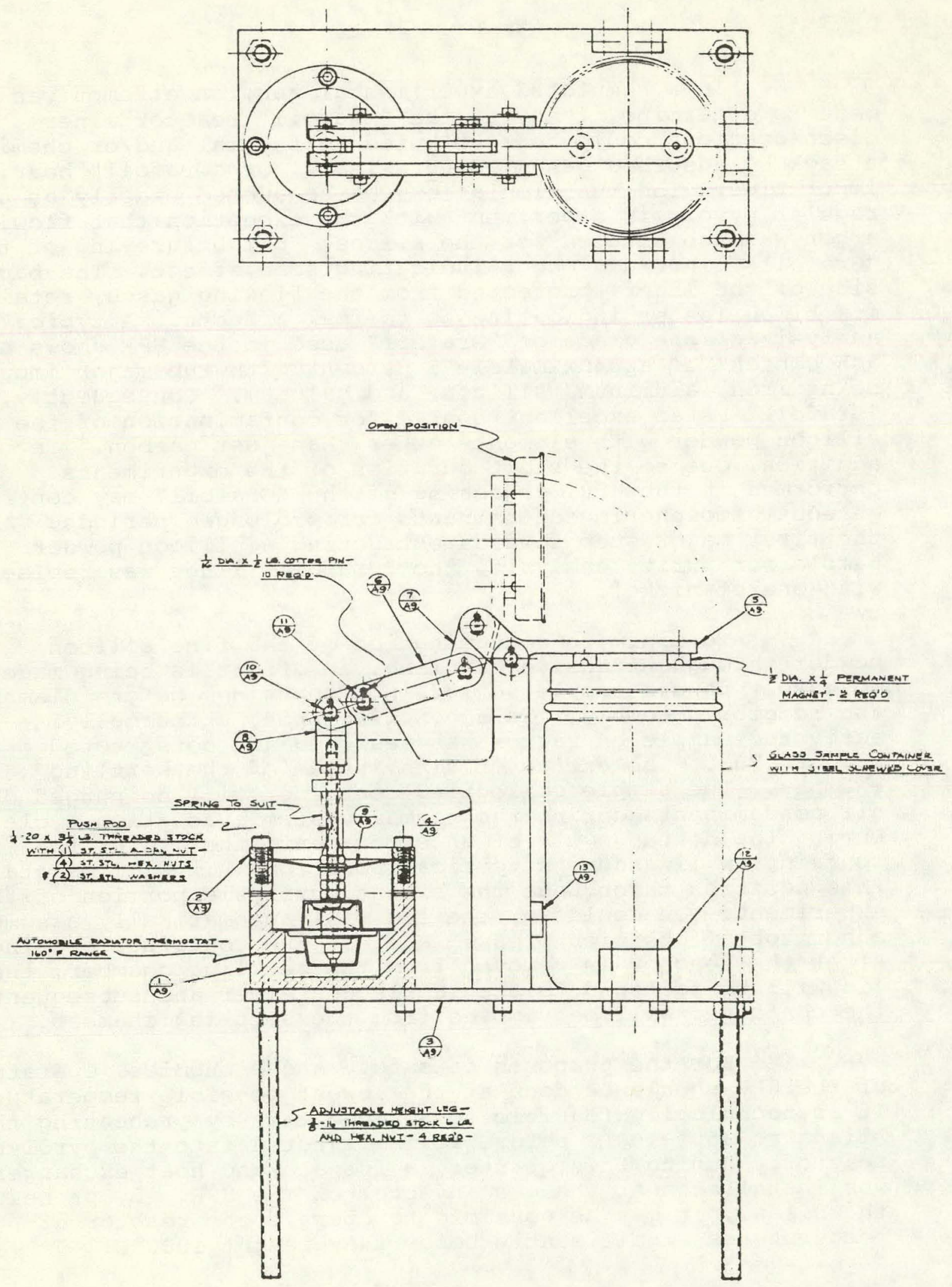

Figure 7B. Sample Collector Assembly Sketch. 
Figure 8B shows Scanning Electron Microscope photomicrographs of HPR powders produced under various silane flow conditions. The photomicrographs are of settling chamber powders from Experiments HPR-271-12-3 (photo No. 27022302-3-S2), HPR-626-1-1 (photo No. 2702230L-1-S1), and HPR-626-1-2 (photo No. 27022302-2-S1). The particle diameter can be compared to the average values given in Table $I$. The average values are calculated from surface area determination (by nitrogen adsorption) assuming spherically shaped particles.

II. POWDER CONSOLIDATION

Furnace capabilities are needed to determine if powder consolidation (melting, casting, or sintering) concepts are technically obtainable. During the startup phase of this program, the temperature capability and operating suitability of a controlled atmosphere resistance furnace was evaluated. The furnace was considered suitable for the present program; it was dismantled, transferred, and reassembled in a laboratory area assigned to the silicon project.

The objectives of the melt consolidation experiments performed during this quarter focused on obtaining the engineering and design data for a melting furnace that can be placed inside of the HPR settling chamber. Silicon powder produced in the HPR was successfully melted in the resistance heated vacuum furnace and cast in a quartz crucible. A powder feed system was devised to simulate the conditions of melting and casting inside the settling chamber. Some of the engineering and design problems have been identified and will be addressed.

A single experiment demonstrated that the HPR powder can be consolidated by a sedimentation and evaporation process. The density of a sample of silicon powder increased from $0.025 \mathrm{~g} / \mathrm{cc}$ to $0.20 \mathrm{~g} / \mathrm{cc}$ simply by wetting a crucible of the powder with acetone and subsequently evaporating the acetone. In the near future, the sintering behavior of these compacts, pressure pelletized compacts and loose powder will be studied to determine if sufficient agglomeration occurs to convert the submicron powder into a Fluid Bed Reactor feedstock.

\section{CONCLUSIONS}

During this quarter, silane $\left(\mathrm{SiH}_{4}\right)$ was pyrolyzed in the free space of the current High Purity Reactor (HPR) under conditions that indicate high decomposition rates are possible in a modest size reactor. Continuous operation has not been 

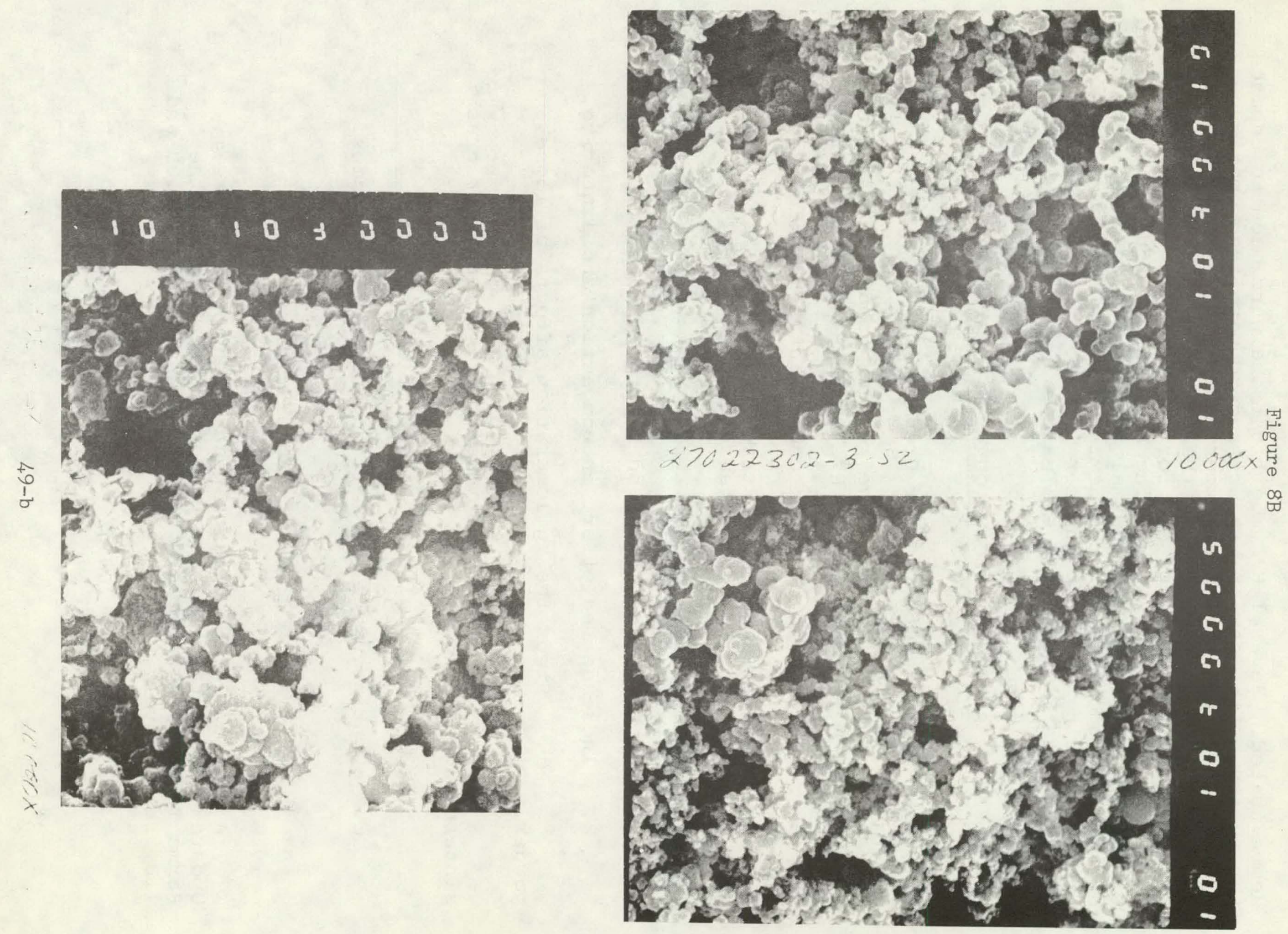

$$
2702230 i-2-31
$$


demonstrated. Several HPR modifications were made to enhance the purity of the powder product and to permit automatic sample collection during an experimental run. Equipment was also installed for preheating the silane gas before it is injected into the reactor and for consolidation of the powder. Some of the engineering and design problems associated with powder transfer and thermal treatment have been identified and will be addressed in the next quarter. The powders produced during the next quarter will be of sufficient purity to justify chemical evaluation.

\section{PROJECTED SECOND QIIARTER ACTIVITIES}

I. Free Spacc Reactor Fowder Preparraliun

A. Continue to study the reactor condition effects upon the form and size of the particles produced.

B. Continue to evaluate powder-gas separation techniques.

C. Evaluate means of extracting samples for analysis with minimum handling and contamination.

II. Powder Consolidation

A. Complete the Fluid Bed Reactor data summation.

B. Increase the effort in compaction and sintering. powder.

1. Study the ayylumeration affects of loose sintered loose powders.

2. Study the particle distribution after crushing 3. Sludy dlternatc compaction methods.

c. Continue with the melting and casting studies. PROGRAM STATUS UF'DA'IE

A revised Implementation plan is shown in Figure 9B. Updated Direct Labor Hours and Total Cost Plan for the Parma Technical Center effort are shown in Figures $10 \mathrm{~B}$ and 11B, respectively. 
Figure 9B

PARMA TECHNICAL CENTER

TENTATIVE IMPLEMENTATION PLAN*

JPL Contra:t No. 954334 Modification No. 6

Year

Month of Year

Month of Contract

I. Free Space Reacior Powder Preparation

A. Reactor condition effects on particle morphology

B. Output withdrawl criteria

1. Powder-gas separation

2. Powder sample extraction

II. Powder Consolidation by Fluid Bed and Alternate Means

A. Summarize Fluid Bed Reactor pyrolysis data

B. Study various consolidation method:

1. Powder corpaction and sintering

2. Powder melting and casting

C. Fluld Bed Reactor particle behavior tests

III. Study the Behavior of Most Promising System

A. Demonstrate efght-hour continuous operation

B. Demonstrate five-, eight-hour shift operations

C. Conduct englneering process studies

1. Minimize wall reactions

2. Minimize injector cone formaticns

3. Study operating parameter effects on rates

4. Determine pyrolysis efficiency

5. Determine current reactor product cost

D: Characterize product form and size

E. Evaluate product purity

IV. Preliminary Design for Pilot Plant Pyrolyzer

A. Engineering consideration for hydrogen recovery

B. Estimate pilot plant cost

C. Estimate pilot plant product cost

V. Reports
A. Month1y
B. Quarterly
C. Annual
D. Final

$\star \Delta=$ Decision Milepost

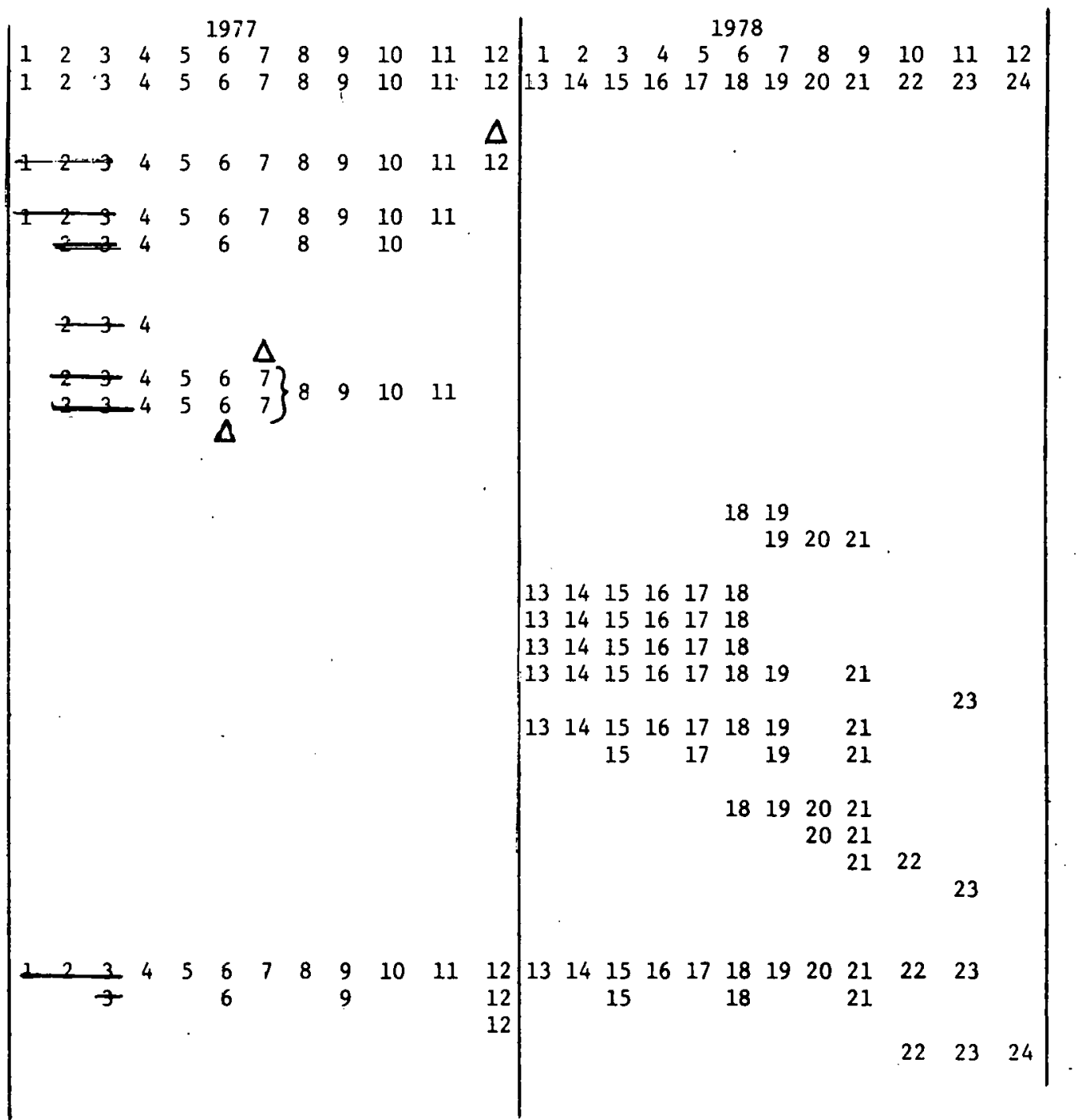

G770518 
Figure 10B

PARMA TECHNICAL CENTER

Direct Labor Hours Planned for the High Purity Silicon Project Contract No. 954334

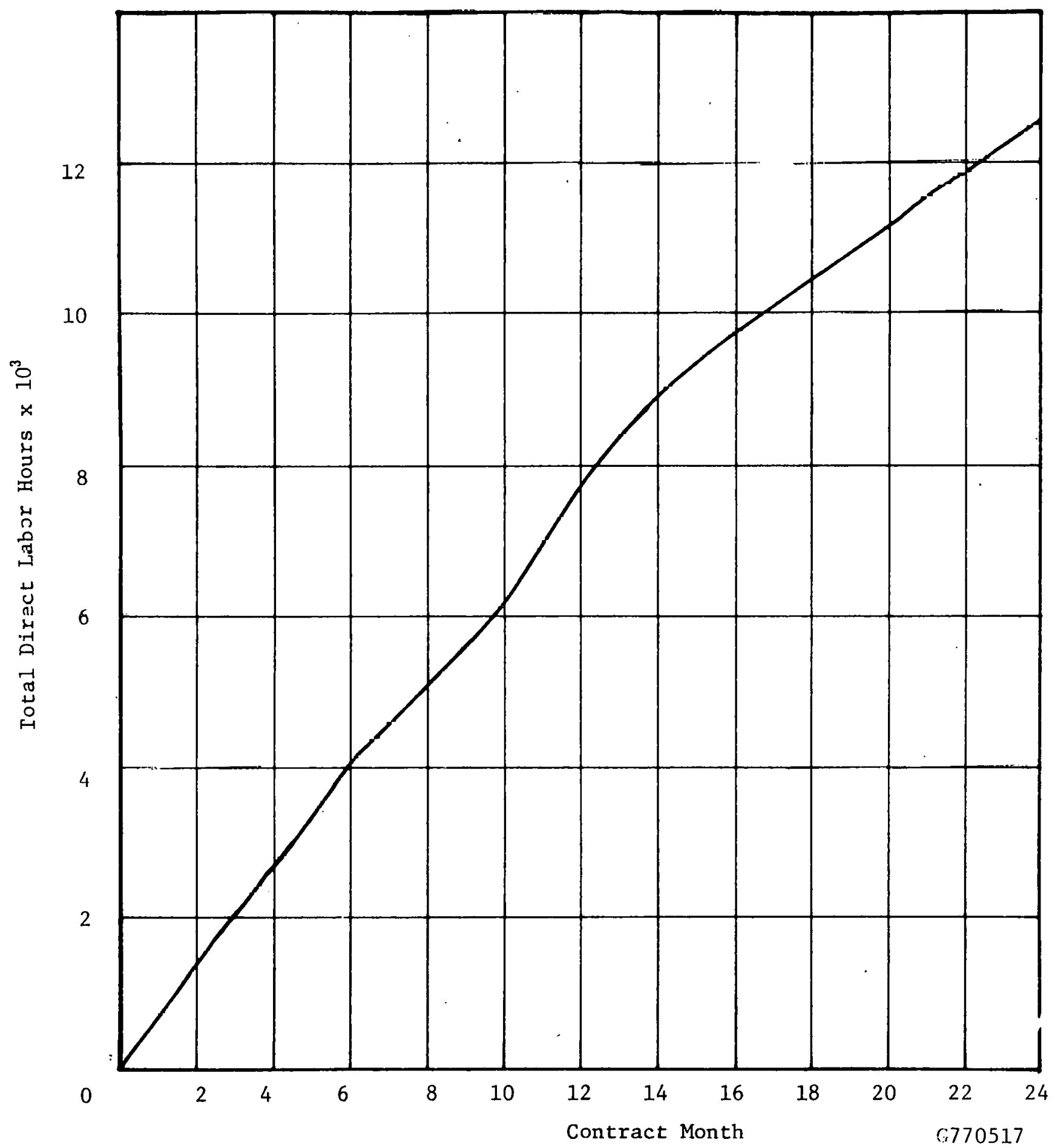


Figure 11B

PARMA TECHNICAL CENTER

Total Cost Plan for the High Purity Silicon Project Contract No. 954334

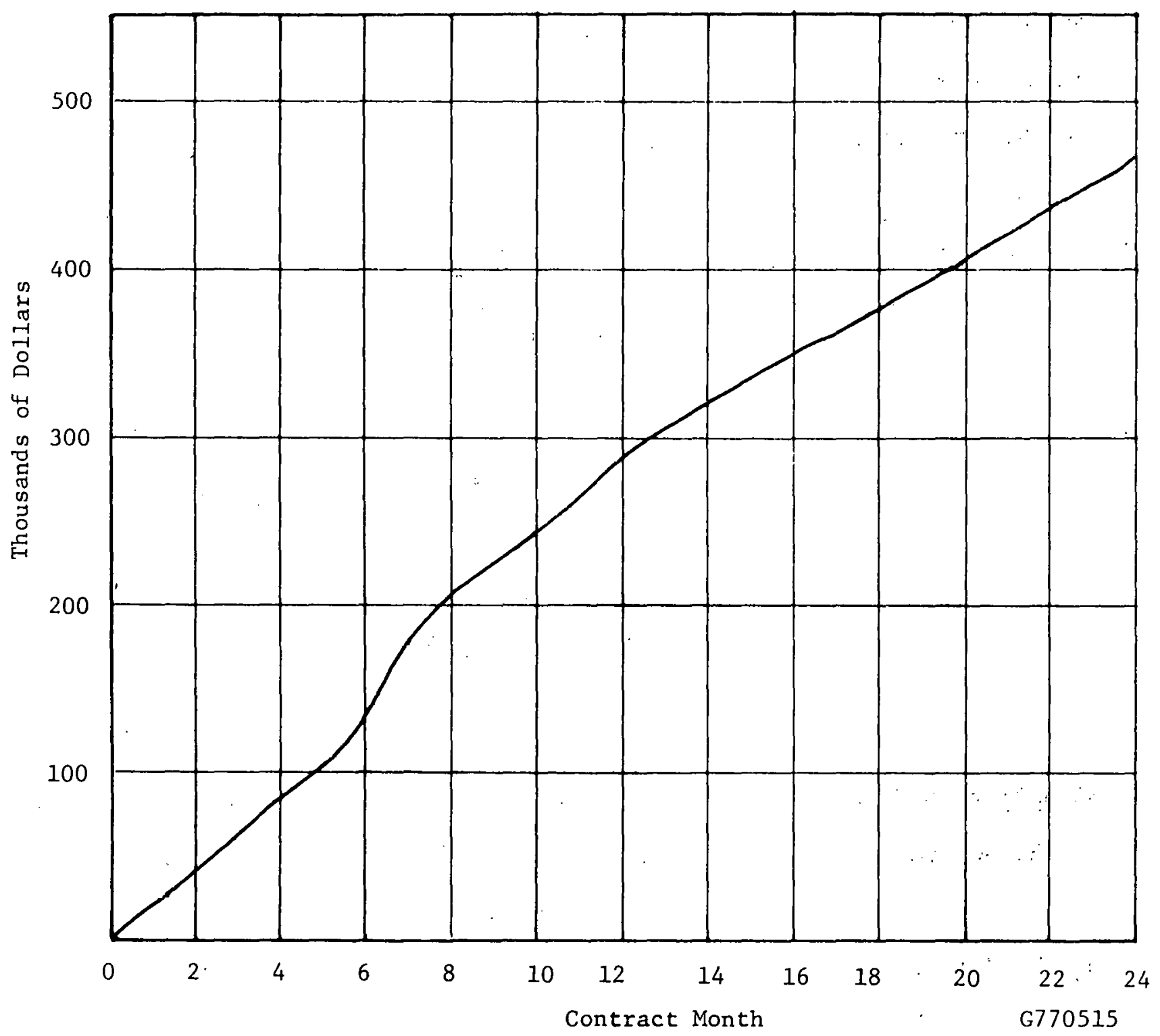


INTERNAL DISTRIBUTION LIST

Quarterly Progress Report April 1, 1977

$\underline{\text { PART VI }}$

\section{SISTERSVILLE}

T. H. Barker

W. C. Breneman

T. K. Ioaninụu

L. Madestau - 2

G. M. Omietanski

G. G. Weimer

Library - 3
TARRYTOWN

D. I. Bailey

J. R, Barber

H. Kanner

P. Kotval

P. R. Kinkel

J. E. Mckeon

J. Y. P. Mui

P. J. Orenski

D. F. Pollart

S. Sterman

J. F. Tancredi

S. Tinsley

Cover Sheet - 66

Library - 3
PARMA

W. E. Chambers

R. J. Dufala

R. J . Elvert

E. G. Farrier

M. R. Malay

J. T. Meers

J. Rexer

R. L. Robinson

L. D. Stoughton

G. E. Whitmargh

Tibrary
WASHEINGTON D.C.

C. E. Winters

BOUND BROOK

B. D. Marsh
NEW YORK

J. Hart Evans

M. H. Jellinek

G. A. Keig

L. Shechter
SOITH PLAINFIELD

E. Erb

SOUTH CHARLESTON

B. Fonville 